Portland State University

PDXScholar

6-2-1995

\title{
The Origins of Caring: A Study of the Development of Coding Categories for Prosocial Behaviors in Very Young Children
}

Mark W. Schuster

Portland State University

Follow this and additional works at: https://pdxscholar.library.pdx.edu/open_access_etds

Part of the Psychology Commons

Let us know how access to this document benefits you.

Recommended Citation

Schuster, Mark W., "The Origins of Caring: A Study of the Development of Coding Categories for Prosocial Behaviors in Very Young Children" (1995). Dissertations and Theses. Paper 5044.

https://doi.org/10.15760/etd.6920

This Thesis is brought to you for free and open access. It has been accepted for inclusion in Dissertations and Theses by an authorized administrator of PDXScholar. Please contact us if we can make this document more accessible: pdxscholar@pdx.edu. 


\section{THESIS APPROVAL}

The abstract and thesis of Mark W. Schuster for the Master of Science in Psychology were presented on June 2, 1995, and accepted by the thesis committee and the department.

COMMITTEE APPROVALS:
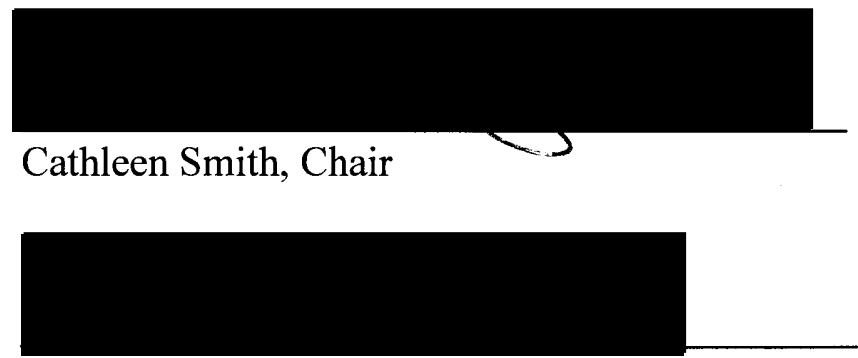

Thomas Kindermann

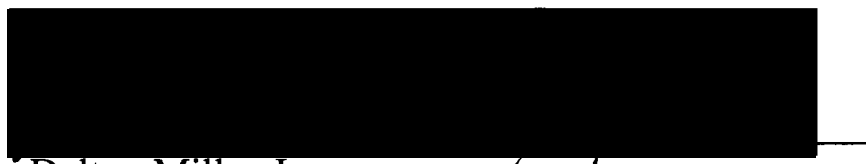

Dalton Miller-Jones
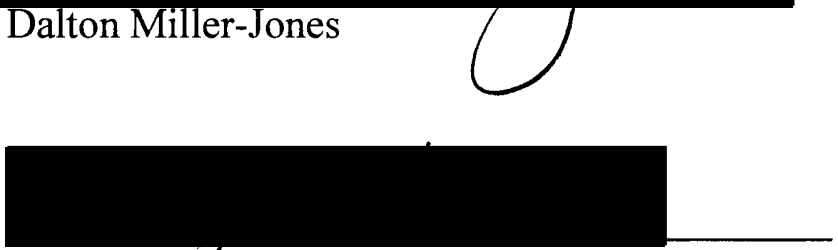

Amy Driscoll

Representative of the Office of Graduate Studies

DEPARTMENT APPROVAL:

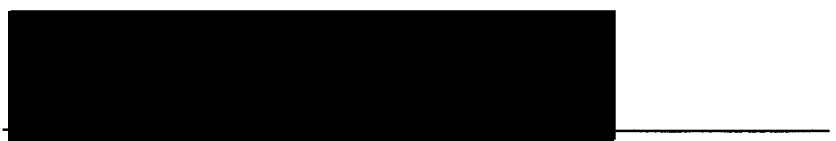

Jim Paulson, Chair

Department of Psychology

$* * * * * * * * * * * * * * * * * * * * * * * * * * * * * * * * * * * * * * * * * * * * * * * * * * * * * * * * * * * * * * * * * * * * * * * *$

ACCEPTED FOR PORTLAND STATE UNIVERSITY BY THE LIBRARY

by

on

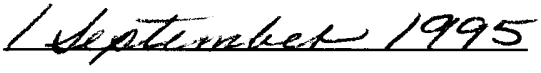




\begin{abstract}
An abstract of the thesis of Mark W. Schuster for the Master of Science in Psychology presented June 2, 1995.
\end{abstract}

Title: The Origins of Caring: A Study of the Development of Coding Categories for Prosocial Behaviors in Very Young Children.

There has a great deal of research regarding the positive social (prosocial) behaviors of young children. Children have been observed performing a number of different prosocial behaviors, including helping, showing, sharing, and responding to the distress of another. However, most of the previous research was conducted in laboratory settings. In order to describe the first manifestations of prosocial behaviors more accurately, research needs to be conducted in a natural setting.

The purpose of the current study was to observe the origins of the prosocial behaviors of young children in a child development center. To accomplish this goal, a research team was assembled and pilot observations were made. Group meetings served as a forum for developing a coding system. The study included four observation periods over a six month span during which children's naturally occurring social interactions were videotaped. Thirty-seven children between the ages of 9 months and 3.5 years who attended a corporate affiliated child development center participated in the study. The first observation period included 37 children who were videotaped for an average of eighty-four minutes each. The three remaining observation periods included 21 children who were videotaped an average of ninety minutes each. Approximately 150 total hours of videotape were collected.

In addition to developing a coding system, a reliability study was conducted. This study included 42 three-minute segments which were representative of the videotape that was collected. Also, all the behaviors under observation were included among these 
segments. The three newest members of the research team then coded the segments. Inter-observer agreement was assessed by computing percentage agreement and also by calculating Cohen's kappas. Repeated measures analysis of variance were performed to determine if there were differences between observers, across the age range of the children, or across the group activity that the children were involved in while being observed. Although there were no significant differences between kappa values, there were differences between the percentage agreements. The implications of these differences to the coding system is discussed and predictions pertaining to the frequency of prosocial behavior are elaborated. 
THE ORIGINS OF CARING: A STUDY OF THE DEVELOPMENT OF CODING CATEGORIES FOR PROSOCIAL BEHAVIORS

IN VERY YOUNG CHILDREN

\author{
by \\ MARK W. SCHUSTER \\ A thesis submitted in partial fulfillment of the \\ requirements for the degree of

\section{MASTER OF SCIENCE in PSYCHOLOGY}

Portland State University

1995 
The Origins of Caring: A Study of the Development of Coding Categories For Prosocial Behaviors in Very Young Children

A topic that historically has interested philosophers and psychologists regards human nature. Some believe that humans are, by nature, egotistical and selfish; others have postulated that humans are born with the capacity to interact in a positive social manner, and others have maintained that human nature is morally ambivalent (RadkeYarrow, Zahn-Waxler, \& Chapman, 1982). An underlying assumption of this thesis is that humans can, and do, behave in a socially positive manner virtually from birth. In the following, the major theories of prosocial development will be described before a summary of the research on young children's prosocial tendencies is given. Based on this review of the empirical research studies focused on the development of positive social behaviors, a short-term longitudinal observational study was conducted of young children's prosocial behavior in a natural setting. For this study, a complex coding procedure was developed, its reliability assessed, and a training manual for learning the coding system was developed.

The conventional definition of positive social, or prosocial, behavior is "any behavior that is carried out for the benefit of others" (Radke-Yarrow et al., p. 469). A partial list of behaviors considered to be prosocial would include helping, sharing, and aiding another in distress.

Theories of Prosocial Development

The motivation to perform prosocial behaviors has been addressed by several theories of development, including psychoanalytic theory, cognitive developmental theory, learning theories, and evolutionary theory from a sociobiological perspective. The relevance of these theories for prosocial development is reviewed by Radke-Yarrow 
and her colleagues (1982). The major points will be summarized here.

Psychoanalytic Theory. The psychoanalytic explanation for prosocial behaviors weighs heavily on the concept of identification. This process is thought to be the means by which societal values become internalized. Identification with another person enables one to experience empathy which is thought to provide motivation to restrict aggression and also to behave prosocially. In addition, identification also provides for the development of the superego which will cause one to feel guilt as a result of moral transgressions. Guilt and empathy are believed to provide the impetus for prosocial behavior.

Cognitive-Developmental Perspective. Issues relating cognitive developmental theories to prosocial behavior are based on the assumption that prosocial behavior develops in conjunction with the child's developing understanding of self and others. J.M. Baldwin (cited in Radke-Yarrow et al., 1982) is credited for creating a stage theory that describes the development of childrens' understanding of themselves relative to other people as well as inanimate objects. Baldwin's theory posits that the self/other distinction is made by the child experiencing the effort associated with his/her own actions but not the actions of others. Baldwin's theory is usually regarded to be the first theoretical framework through which prosocial behaviors of young children can be interpreted.

Following Baldwin, Jean Piaget also described childrens' cognitive development in relation to moral behavior in a stage theory. For Piaget, prosocial behavior develops "as a result of interaction between maturational changes in mental functions and active experience with the physical and social environment" (Radke-Yarrow et al., 1982, p. 472). It is reciprocal interactions with equals (i.e., peers) that lead the child out of the egocentrism that, for Piaget, characterizes the behavior of young children and precludes the expression of truly prosocial behaviors which involve taking the perspective of others. 
The progression away from egocentrism affords the child an ability to take the perspective of another and sets the stage for the development of prosocial behaviors.

Another theorist who has elucidated a cognitive stage theory of moral development is Kohlberg. Like Piaget, Kohlberg's theory is based on an hierarchical arrangement of stages that reflect increasingly more advanced forms of moral reasoning. A point made by Radke-Yarrow and colleagues worth noting is that Piaget and Kohlberg created theories that pertain most directly to "laws, rules, authority, responsibility, equality, and justice" (Radke-Yarrow et al., 1982, p. 472) whereas prosocial issues such as caring, self-sacrifice and need conflicts were not addressed.

Learning Theories. For the learning theorist, prosocial behaviors are acquired the same way that any other behavior is acquired, through reinforcement and modeling. For the strict learning theorist, the inclination to behave prosocially does not stem from affective states but is totally dependent on the contingencies delivered by the social environment. However, Mowrer and Aronfreed have suggested that affective states, in conjunction with observation and imitation, play a role in the acquisition of prosocial behaviors (cited in Radke-Yarrow et al., 1982). The underlying assumption is that observation and imitation exert an influence on the tendency to behave prosocially. Mowrer and Aronfreed have advanced the idea that for observation and imitation to exert this influence on performance, the reinforcement value must be conveyed from the actor who is directly reinforced to the observer (cited in Radke-Yarrow et al., 1982). In other words, for the observer's performance to be influenced, he or she must have some idea of the positive or negative value that the reinforcement exerted on the actor. Mowrer and Aronfreed have suggested that affect expressed by the actor may facilitate this transmission. Accepting this idea broadens the scope of social learning theory to include the study of expressed affect and the interpretation of others' affective expressions.

Evolutionary Theory. Evolutionary theory from a sociobiological perspective 
postulates an interesting claim regarding the motivation to perform prosocial behaviors. From this perspective, prosocial and altruistic behaviors must provide an evolutionary benefit. Providing an evolutionary benefit entails increasing the genetic fitness of the individual which is assumed to increase the probability of genetic proliferation. The benefit accrued to an individual who performs altruistic behavior is hypothesized to derive from the expectation of reciprocity. From this perspective, prosocial behaviors are motivated by an expectation of some form of 'payback' in kind, or in time of need. In addition, the 'selfish gene' hypothesis leads to the conclusion that an individual is not necessarily aware of his/her own expectation of reciprocity (Dawkins, 1976).

However, these claims are, at present, untestable. Some researchers have made the distinction between prosocial behaviors and altruism based on the idea of reciprocal expectations (Eisenberg, Cameron, \& Tryon, 1985). They define altruism as the subset of prosocial behaviors that are not motivated by the anticipation of reciprocity or personal benefit. Due to methodological difficulties of distinguishing between prosocial and altruistic behaviors, most researchers examine prosocial behaviors without attempting to identify the underlying, perhaps selfish, motivation. In addition, not all researchers make the distinction between prosocial and altruistic behaviors described above; consequently, in much of the research the terms altruistic and prosocial behavior are used interchangeably.

Summary. Although research on prosocial behavior has not been able to unanimously support or refute any of these theories, it has generated some information concerning the presence of these behaviors in the repertoire of the very young child. The following review is designed to describe the range of prosocial behaviors that have been identified in infants and toddlers.

Several aspects of prosocial development will not be considered here, i.e., the socialization of prosocial behaviors and parental styles conducive to prosocial 
development, cognitive factors influencing prosocial development, and cultural influences on prosocial development. The interested reader is referred to several chapters in the Eisenberg and Mussen (1989) book The Roots of Prosocial Behavior in Children; Eisenberg's (1992) book The Caring Child; the first volume of the Handbook of Moral Behavior and Development (Kurtines \& Gewirtz, 1991); and Carolyn Pope Edward's chapter "Moral Development in Comparative Culture Perspective" in the Wagner and Stevenson (1982) book Cultural Perspectives on Child Development. For a more general audience, Thomas Lickona's Raising Good Children (1983) and Educating for Character (1993) are recommended.

\section{Forms of Prosocial Behaviors}

Before reviewing the research on the specific forms of prosocial behaviors identified in young children, a critical distinction that pertains to all forms of prosocial behavior should be described. Eisenberg and her colleagues (1985) argue that it is important to note whether prosocial behaviors are self-initiated or not. In their terminology, prosocial behaviors are either 'spontaneous' (initiated by self) or 'asked for' (initiated by another). Asked for behaviors are also referred to as "compliant' behaviors. In presenting their argument, Eisenberg and colleagues cite research suggesting that children whose prosocial behaviors were predominantly 'asked for' differed in the patterns of social behavior they engaged in compared to children whose prosocial behaviors were predominantly spontaneous. In addition, these two groups of children differed in the responses they elicited from their social partner (Eisenberg et al., 1985). Preschool children who displayed a higher proportion of spontaneous, self-initiated prosocial behavior were found to be more socially competent and engage in higher levels of moral reasoning. In addition, they were judged to be more assertive with their peers, prone to sympathy rather than self-distress, more independent, and involved in a greater number of positive or neutral social interactions than their peers. Unfortunately, a good 
deal of research has been conducted without making this distinction.

The prosocial behaviors of young children that have been researched most heavily are responsivity to other's distress, sharing, and helping.

Response to Distress. Responsivity to other's distress has been studied by RadkeYarrow, Zahn-Waxler, and their colleagues (Radke-Yarrow \& Zahn-Waxler, 1984; ZahnWaxler, Radke-Yarrow, \& King, 1979; Zahn-Waxler, Radke-Yarrow, Wagner, \& Chapman, 1992) and by other researchers as well (Hay, Nash, \& Pedersen, 1981; Howes \& Farver, 1987). Of all the prosocial behaviors identified thus far, responsivity to the distress of another is by far the most extensively examined. It is one of few prosocial behaviors that has been studied both outside of the laboratory setting and over time.

The data that have been accumulated describe an increase in the complexity of the response form with age over the first two years of life. Initially, infants may attend to another in distress and may become distressed themselves, crying in a manner similar in appearance to a social contagion effect. For older infants, the frequency of self-distress declines and children are more likely to orient themselves to, and attend to, the distressed individual. Beginning in the second year of life, children are able to make active attempts to soothe a distressed individual. By age two, "children bring objects to the person who is suffering, make suggestions about what to do, verbalize sympathy, bring someone else to help, aggressively protect the victim, and attempt to invoke a change in affect in the distressed person" (Radke-Yarrow et al., 1982, p. 481). This change in response form, from a tendency toward self-distress, to a more passive attending to distress, and then to active attempts to comfort the distressed individual, is attributed to childrens' developing ability to distinguish self from other. Zahn-Waxler et al. (1992) credit Hoffman (1975) for providing the conceptual framework through which their data are interpreted. His theory emphasizes a transformation within the individual from self-concern to empathic concern for others. Hoffman theorizes that this transformation is facilitated by the 
development of self-awareness and the differentiation of self from others (cited in ZahnWaxler et al., 1992). Hoffman (1975) postulates that there is a biological predisposition for feelings of empathy which results in the self-concern that characterizes the infant's initial distress response.

A major obstacle that must be overcome in studying young children's response to distress is the problem of adequate sampling strategies. Opportunities to record responses to distress may be hampered by the low frequency of distress occurrences in the children's environment.

A method utilized by the research team lead by Hay was to bring pairs of six month children into the lab (Hay et al., 1981). The infants were videotaped in ten minute intervals which were then coded for the presence of distressed vocalizations of one or both infants during five second units. Hay and colleagues found that the distress of a peer had a cumulative effect on the individual. This lead to the suggestion that the longer the duration and the greater the intensity of the peer's distress, the more likely an infant is to become distressed him- or herself. However, self-distress was not the only reaction of these six-month olds. Nine of the nineteen infants who had the opportunity to witness distress responded by either "leaning toward, gesturing toward, touching, or otherwise contacting the peer" (Hay et al., 1981, p. 1073). The implication is that the frequency of self-distress in response to distress is beginning to decline at this age and the precursors that may develop into the ability to take an active role in comforting are beginning to appear.

Another method used to study the emergence of comforting another in distress is to train mothers to observe and record, in narrative fashion, incidents of distress and their childrens' responses to distress immediately after they occur in a home environment (Radke-Yarrow et al., 1979; Zahn-Waxler et al., 1992; this method is reviewed in RadkeYarrow \& Zahn-Waxler, 1984). A primary advantage of this method of data collection is 
that since mothers collect the data about their children, many of the difficulties associated with studying individual children in their natural environment over time are eliminated. In this particular case, the waiting associated with trying to observe behaviors that occur infrequently were eliminated by training the mother, who was already with the child, to make the observations in her own home.

The validity of this observational method gained support through a study by Zahn-Waxler and her colleagues (1992) in which mother's reports compared favorably to reports of independent observers. Reliability estimates were obtained by having a trained observer, in addition to the mother, record incidents of the infant's distress response. Although both records pertained to the same event, it is important to note that the events recorded were the children's reaction to simulations of distress as opposed to naturally occurring distress. This underscores the difficulties researchers have had in obtaining naturalistic data on the development of comforting and concern for distressed others.

In sum, there is a need for longitudinal, naturalistic data to confirm the age changes that are hypothesized to occur in the topology of responses to distress i.e., from a tendency toward self-distress in response to distress for very young infants, to a more controlled attention to distress, and finally, by the second year of life, to the ability to make active attempts to alleviate other's distress.

Sharing, Showing, and Pointing. Another prosocial behavior that children under two years of age have demonstrated is the capacity and willingness to share. Sharing has been defined as giving, showing, and cooperatively manipulating objects in the possession of another (Rheingold, Hay, \& West, 1976; Hay, 1979; Hay, Caplan, Castle, \& Stimson, 1991).

Rheingold and her colleagues (1976) defined giving as the child's release of an object into another's hand or lap. They defined showing as directing a person's attention to an object by holding it toward the person and looking at him/her or by pointing to it. 
Cooperatively manipulating an object that is still in contact with the other person was termed partner play. In a laboratory setting, all of the 18-month-old children who took part $(\mathrm{n}=111)$ displayed some form of sharing with their parents (Rheingold et al., 1976).

In another laboratory study that included 12-, 18-, and 24-month old children, it was demonstrated that sharing behaviors increased with age. Of the eight children observed at each age group, seven of the 12-month old children, and all of the 12- and 24month old children were observed sharing with their parents (Hay, 1979). Subsequent laboratory research conducted by Hay and colleagues has documented that children in the second year of life are more likely to share with peers when there is a low cost for sharing (i.e., an abundance of toys or duplicate toys available : Hay et al., 1991). Hay and her colleagues suggest that sharing in the second year of life becomes more of a rational decision than a vehicle for social interaction.

Following the suggestion of Eisenberg and colleagues (1985) that spontaneous sharing would be a better predictor of prosocial behavior than requested sharing, Hay and her associates examined this aspect as well. They found no age differences in the frequency of spontaneous sharing; however, requesting that a peer share was less effective in the second year than in the first year. It is interesting to note Hay's comment that the "relation of these activities to later sharing and cooperation is unclear" (Hay, 1979, p. 647). This is due, in part, to the fact that these behaviors in children this young (under 18 months of age) have not been studied longitudinally or in natural settings.

Pointing as a means of affective sharing is believed to be a precursor of showing and of sharing. Leung and Rheingold have sought to determine the earliest age at which pointing as a means of sharing emerges (Leung \& Rheingold, 1981). They observed infants in a laboratory who were between the ages of 10.5 and 16.5 months and coded for reaching and pointing behaviors. It was found that pointing as a means of communicating was present by 12.5 months in the majority of children (Leung \& 
Rheingold, 1981).

Pointing can accomplish two separate goals for the child. Pointing can serve as a request for an object out of reach. In the above case, pointing was an instrumental act. However, a child may also point to direct one's attention to an interesting object in order to share the experience. This would be a case of pointing as affective sharing. It may be important to distinguish between pointing as an instrumental act and as a means of affective sharing when studying prosocial development. However, the distinction is difficult to make and was not made or even commented on by Leung and Rheingold. In addition to the limits imposed in a laboratory setting, this makes it difficult to generalize about the prosocial nature of the pointing these infants displayed.

As an interesting note, researchers in another field of study have documented that deficits in the infant's ability or willingness to engage in pointing and related activities, which they term 'joint-attention activities', are associated with autism, and more specifically, with the degree of the autistic's language deficit (see Baron-Cohen, 1989; Mundy \& Sigman, 1989; Harris, 1989; Hobson, 1989; Leslie \& Happe, 1989). Jointattention activities include showing, sharing, pointing, and referential gazing, which is defined as alternating the direction of visual gaze between a person and an object. BaronCohen speculates that deficits in joint attention activities are "autism-specific, and may be the earliest manifestations of autism yet identified" (Baron-Cohen, 1989, p. 185). This finding highlights the need for longitudinal descriptive data on children's tendencies to give, show, and point out interesting objects to other people in natural settings.

Affection. The tendency of very young children to engage in affectionate behaviors with siblings has been examined longitudinally by Abramovitch and colleagues (Abramovitch, Corter, \& Lando, 1979; Abramovitch, Corter, Pepler, \& Stanhope, 1986). In these studies, physical affection was defined as "positive physical contact, specifically: hug, kiss, hold hands, pat" (Abramovitch et al., 1979, p. 1000). In 
addition, verbal affection, defined as praise, approval or verbal comforting, was also examined. The average age of the children at the beginning of the study was 20 months for the younger siblings and 41 months for the older siblings. The children were observed in the home at three measurement points over a three-year period. The results of the study indicated that physical affection declined steadily with age but verbal affection increased with age (Abramovitch et al., 1986). Affectionate behavior between peers (who are not kin) was not examined.

Caregiving. Rheingold and Emery (1986) sought to determine the earliest age at which young children perform behaviors that resemble the nurturant acts that parents carry out in taking care of their relatively helpless infants. These behaviors include fulfilling the biological needs of the young child such as feeding, cleaning, protecting, and keeping warm. They also include acts that aid in the socialization of the child such as talking to, instructing, and playing with the child. These behaviors are referred to as 'nurturing' or 'caregiving'. When very young children perform these behaviors the recipients are often dolls or other inanimate objects. In a laboratory setting, Rheingold and Emery (1986) demonstrated that children as young as 18 months will perform a number of behaviors that fit this description of caregiving. All the children they observed directed some form of nurturant act, i.e., feeding, putting to bed, caressing, disciplining, grooming, sharing, or talking to dolls or stuffed animals. It was found that the frequency of these behaviors increased steadily with age up to thirty months (the oldest children they observed). In addition, children also directed nurturant behaviors toward their parents. To date, these behaviors have not been studied in a natural setting or over time.

Helping. Another category of behaviors considered prosocial is helping behaviors. That children as young as 18 months will help their parents with domestic chores has been documented by Rheingold (1982). She brought 60 children between the ages of 18 and 30 months with their parents into the lab. The experimental setting simulated a 
household with nine household chores that were uncompleted. These chores included picking up a scattered deck of cards and a pile of magazines in disarray, dusting, making a bed, folding laundry, and the like. Parents were instructed to begin performing the tasks slowly and also to inform their child which task they were about to perform. After the twenty five minute trial period, the experimenter entered with a bag of groceries to put away. The childs' behavior was videotaped and subsequently coded for helping behaviors.

Although this environment was especially conducive to these types of helping behaviors, which they termed nascent helping, "all the children, even at 18 months of age, not only participated in their parent's performing of the tasks but did so to a considerable extent" (Rheingold, 1982, p. 117). Rheingold makes the argument that since the children aided their parents and did so in a manner appropriate to the task at hand and also displayed knowledge of the parents' goals, these behaviors were a benefit to the parents and therefore qualify as prosocial. Unfortunately, naturalistic data specifically addressing these types of helping behaviors are not available.

Marcus (1986) has reviewed twelve different studies concerned with helping behaviors to real persons (as opposed to dolls or inanimate objects). Interestingly, none of the studies reviewed included children younger than 3 years of age. By noting the commonalities of the studies, Marcus arrives at a definition of helping as any behavior in response to another's nonemotional needs. Responses to nonemotional needs may take the form of facilitating another's activity or retrieving a lost or dropped object (Marcus, 1986).

Teaching. The rationale for including teaching as prosocial behavior in children is reviewed by Staub (1979). Smith, Leinbach, Stewart, and Blackwell (1983) conducted a study showing that preschool children (4-5 years old) were willing to instruct another person who verbalized a need (e.g., "I don't know how to..."). Pratt, Scribner, and Cole 
(1977) have demonstrated that preschoolers (the average age of the group was 5.6 years) will adapt the content of their speech to listener needs. An open research question is whether children younger than the children tested in both of these studies attempt to instruct others, or even if the opportunity for doing so will arise in a naturalistic setting.

Compliance. Kochanska $(1991,1993)$ has argued that children must develop the capacity for behavioral control in order to refrain from wrongdoing and engage in moral conduct. The overt manifestation of this capacity is the child's compliance with parental standards and requests. In Kochanska's model, early compliance with caregivers is considered to be a precursor to "conscience" or internalization (i.e., the avoidance of transgression and the demonstration of empathy and prosocial behavior in the absence of surveillance). However, as Kochanska herself notes, it remains to be seen whether very young children's compliance to everyday caregiver demands, observed in naturalistic contexts, predicts future "conscience" measures (Kochanska, 1993). The capacity for behavioral control, i.e., behavioral self-regulation, is a complex process that develops gradually, emerging in the second year of life. It coincides with parental expectations that the child will begin to display it (Kochanska, 1993). Kopp (1982) has provided a detailed description of this process; Gralinski and Kopp (1993) have shown that rules that are emphasized earliest in the second year-- safety, protection of personal property (e.g., "Don't color on the walls"), and respect for others (i.e., rules regarding the expression of prosocial, and the control of aggressive, behavior) --are the ones for which compliance is greatest.

Cooperation with the Entry Bid of a Peer. In a personal communication to Dr. Cathleen Smith, Dr. Thomas Lickona (10-8-93) expressed his belief that highly prosocial infants can be identified by their willingness to cooperate with entry bids made by peers. An entry bid is any attempt by a child to begin a new social interaction with a different social partner. Lickona asserted that accepting an entry bid, or "allowing another person 
into one's psychological space", is an early hallmark of prosocial children. Howes, Galluzo, and Meyer (1986) observed different responses made by children to the entry bids of their peers. First, they identified as entry bids any attempt to initiate a social play interaction with another that included looking at the social partner while attempting to share an object, making a verbal request to play, or engaging in a parallel activity with objects. After identifying children's entry bids, it was possible to categorize four different response forms: cooperating with, ignoring, rejecting, or aggressing against the individual who had made the entry bid (Howes et al., 1986).

Assertive Problem Solving. Fabes and Eisenberg have examined children's episodes of interpersonal anger and related them to measures of social competence and popularity (Fabes \& Eisenberg, 1992). They argue that children who are judged to be higher in social competence and popularity will be more likely to cope with interpersonal conflicts "in relatively nondisruptive and direct ways (e.g., they would aggressively retaliate infrequently and actively pursue what they believe to be in their best interests relatively often" ( Fabes \& Eisenberg, 1992, p. 117). Compared with the alternatives, this is considered to be the most prosocial strategy for resolving conflicts. The study was observational and conducted at a university affiliated child care center. For each anger episode observed, the cause of the child's anger was coded into one of five possible causal categories (i.e., being the target of either physical or verbal aggression, being socially rejected, having property or space taken, or being forced to comply). His or her coping strategy was coded into one of seven coping categories (seeking revenge, actively resisting, venting emotions, stating dislike and rejecting, adult seeking, avoidance, and 'other'). The 'actively resisting' category was defined as defending oneself in nonaggressive ways (Fabes and Eisenberg, 1992). Teacher ratings were used to estimate social competence and popularity.

Children rated high in social competence and popularity were observed to be 
involved in fewer anger conflicts. Of the five causal categories, having possessions or space taken and being physically aggressed upon were the two most common causes of anger in young children. A gender difference was found indicating that girls were more likely to use active resistance as a coping strategy than boys. In addition, boys coped by venting their emotions (sulking, crying, or throwing a tantrum) more frequently than girls. An interesting note is that observers coded 'other' as a coping response to anger in boys almost twice as frequently as for girls (it was slightly below 'revenge' as the fourth most common coping strategy for boys).

Studies of Multiple Prosocial Behaviors. Few studies to date have examined more than one of the behaviors described here as prosocial conjointly. Bar-Tal, Raviv, and Goldberg (1982) examined four types of prosocial behaviors among children in nursery school and kindergarten settings who were between the ages of 18 and 76 months. Prosocial behaviors were observed during play with regard to whether they were 'pretend' activities or 'real' acts with other people. The prosocial behaviors coded were: sharing, giving, aiding, and comforting. Sharing was defined as donating part of the object or objects in an individual's possession to another. Giving was defined as donating the whole of the object (Bar-Tal et al, 1982). In addition, behaviors were coded with regard to whether they were self-initiated, initiated by request, or imitated. Also examined was the reinforcement of such behaviors categorized into four groups: no reward, social reward, tangible reward, or threat (i.e., after non-compliance with a requested behavior).

The authors were able to draw a number of interesting conclusions from the data. They found no gender differences in the frequency of prosocial behaviors nor was there a significant difference between gender groups in the overall number of children who performed prosocial behaviors. However, there were age differences in the frequency with which children performed prosocial behaviors: frequencies of prosocial behaviors 
decreased steadily from under 30 months to 54 months and then increased with age (final age range tested $=67-76$ months). In addition, the proportion of pretend prosocial behaviors to real prosocial behaviors steadily decreased. This was attributed to an overall decrease in time spent in pretend play. Also important to note is that the large majority of prosocial behaviors were not rewarded either tangibly or socially. In fact, during the observation trials no prosocial behavior was rewarded tangibly.

\section{Aggression and Noncompliance}

In one of the most important and oft-cited studies in the prosocial development literature, Zahn-Waxler and colleagues (1979) showed that children who were most prosocial in response to another's distress had mothers who pointed out the importance of not hurting others when their children had themselves caused another's distress, e.g., when their child had been aggressive and hit another child. In other words, episodes of aggressive behavior provide a potential arena for prosocial development. As a result, the study of prosocial development is aided by focusing on moral transgressions as well as on prosocial behaviors. However, the association between prosocial and antisocial behavior in young children remains decidedly unclear. Depending on the qualitative characteristics of the prosocial and antisocial behaviors studied, as well as the characteristics of the child and the context, correlations are positive, negative, mixed, or nonexistent (Cummings, Hollenback, Ianotti, Radke-Yarrow, \& Zahn-Waxler, 1986).

Noncompliance with parental requests also has been considered a potential arena for prosocial learning to occur. In studying childrens' noncompliant episodes, Patterson (1982) has described an escalating chain of events which begins with the child's noncompliance to a parental request. The aversive reaction produced by the child's initial noncompliance leads some parents to become emotionally charged. This can cause the parent to modify or abandon his or her request after successive attempts to persuade or coerce the child to comply have failed. The child's successful attempts at defying his or 
her parent's request are suspected to reinforce the child's initial noncompliant behavior. This process is seen as an example of how behavioral problems that can lead to coercive family interactions, poor peer relationships, poor academic performance, and delinquency may develop. However, Kuczynski and Kochanska have pointed out that noncompliance to parental commands and requests "occurs too frequently to be conceptualized exclusively in terms of childhood dysfunction" (Kuczynski and Kochanska, 1990, p. 398). They cite research from Forehand (1977) and Patterson and Forgatch (1987) that documents noncompliance rates from $20 \%$ to $50 \%$ of the parental commands and requests that were made. In other words, as many as half the requests and commands parents made resulted in childrens' noncompliance.

Kuczynski, Kochanska, and their colleagues have sought to differentiate between different forms of noncompliance to parental requests and commands (Kuczynski, Kochanska, Radke-Yarrow, \& Girnius-Brown, 1987; Kuczynski \& Kochanska, 1990). The goal of their research was to distinguish between noncompliance which is developmentally appropriate and noncompliance which places the child at greater risk for future behavior problems. Developmentally appropriate noncompliance is seen as a child's attempt to exercise his / her developing autonomy and assertiveness. The model of children's noncompliance presented by Kuczynski and Kochanska postulates that unskillful noncompliance attempts by the child are more likely to produce an aversive reaction by the parent and may begin the coercive cycle of events described by Patterson (1982). Unskilled attempts at noncompliance included 'direct defiance', and 'passive noncompliance'. Skilled attempts at noncompliance are believed to be more developmentally advanced and indicative of competence in other areas of social interactions, i.e., they reflect the child's attempts to become autonomous and assertive (Kuczynski \& Kochanska, 1990). Skilled attempts at noncompliance were categorized as 'negotiation' and included making excuses or bargaining. 
To support their model, Kuczynski and his colleagues conducted longitudinal research in a naturalistic setting. They observed children and their mothers in an apartment setting (which was not the participants' home) and coded the style of parental request and the childrens' responses to these requests and commands. Mother-child dyads were observed carrying out typical day-to-day interactions such as preparing and eating lunch. Children were observed once when they were between the ages of $11 / 2$ to $21 / 2$ years and again when they were 5 years of age. Kuczynski and Kochanska found that "only unskillful forms of noncompliance were associated with problematic behavior in children" (1990, p. 402).

\section{The Present Study}

The empirical studies reviewed here clearly demonstrate that very young children are capable of performing and willing to perform a number of different prosocial behaviors. However, there are many questions that remain unanswered. Research is needed that addresses the early manifestations of prosocial behaviors as they develop over time in natural settings. To date, only compliance, response to distress, and affection have been studied longitudinally. Furthermore, most of the prosocial behaviors described above have been studied in laboratory settings only. No study has examined the entire range of prosocial behaviors described here. The following is a description of a research study that addresses these problems. This study examined a broad range of prosocial behaviors in a natural setting over time. Spanning six months, this study was conducted at a high-quality, corporate-affiliated child care center.

\section{METHOD}

\section{Design}

The current study is a descriptive study of children's earliest forms of prosocial behavior. The research design entailed combining a cross-sectional study and a shortterm longitudinal study. This was accomplished by making videotaped observations of 
all children for whom consent was provided at a first measurement point. A subset of those children were videotaped over time at three subsequent measurement points which were approximately one month apart.

While the videotape footage was being gathered, the research team held meetings to refine the coding scheme. After the fourth measurement point was completed, a reliability study was conducted as part of the larger study aimed at determining the readiness of the coding system and areas in the code that could be improved. The results from the reliability study will be described here and are currently being used to finalize the coding scheme. Subsequently, the videotapes will be coded and frequency data on childrens' prosocial behaviors will be obtained.

\section{Participants}

Children. The participants were 37 children who were attending the Thomas Bruggere Child Development Center, a corporate-owned child development center in Wilsonville, Oregon, and their caregivers. Only those children whose parents provided fully-informed consent participated. One child whose parents had initially provided consent was withdrawn from the study at her parents' request. They did however, allow the research team to keep and include as part of the study the videotape focused on their child that had already been collected. Two children stopped attending the center during the study.

The children at the center are grouped by age into three different classrooms. Overall, there were 37 children who participated in the study. Table 1 lists the age, gender, and classroom of each participant. The average age of the participating children in the infant class ( $\mathrm{n}=13$, six girls and seven boys) at the beginning of the study was 43 weeks. In the toddler room the average age of the participating children $(\mathrm{N}=11$, six girls and five boys) at the beginning of the study was 94 weeks. In the transition room, the average age of the participating children ( $N=13$, seven girls and six boys) was 145 
Tabie 1

Participants' Gender and Age in Weeks at both the Beginning and End of the Study

GENDER

\section{Transitioners}

1) $\mathrm{MS}$

2) $\mathrm{CT}$

3) $\mathrm{JN}$

4) $\mathrm{JZ}$

5) $\mathrm{CR}$

6) $\mathrm{EA}$

7) $\mathrm{KL}$

8) JK

9) $\mathrm{CS}$

10) $\mathrm{DB}$

11) $\mathrm{AC}$

12) JC

13) $\mathrm{BF}$
AGE AT BEGIN.

$\begin{array}{ll}163 & 186 \\ 163 & 184 \\ 163 & 184 \\ 161 & 182 \\ 153 & 175 \\ 153 & 123 \\ 150 & 172 \\ 142 & 163 \\ 139 & 161 \\ 135 & 156 \\ 125 & 146 \\ 125 & 146 \\ 119 & 141\end{array}$

86

184

182

175

123

172

163

61

156

46

141

Ave. age $=145.46$

\section{Toddlers}

$\begin{array}{lclr}\text { 1) } \mathrm{AJ} & \mathrm{M} & 109 & 130 \\ \text { 2) } \mathrm{KM} & \mathrm{F} & 106 & 127 \\ \text { 3) } \mathrm{ZS} & \mathrm{M} & 103 & 124 \\ \text { 4) } \mathrm{CS} & \mathrm{M} & 100 & 121 \\ \text { 5) } \mathrm{RC} & \mathrm{M} & 99 & 121 \\ \text { 6) } \mathrm{SD} & \mathrm{F} & 97 & 119 \\ \text { 7) } \mathrm{KW} & \mathrm{F} & 97 & 118 \\ \text { 8) } \mathrm{AL} & \mathrm{F} & 92 & 113 \\ \text { 9) } \mathrm{KM} & \mathrm{F} & 82 & 103 \\ \text { 10) } \mathrm{PK} & \mathrm{F} & 77 & 98 \\ \text { 11) } \mathrm{VP} & \mathrm{M} & 73 & 93\end{array}$

Ave. age $=94.09$

Infants

1) $\mathrm{CC}$

2) $\mathrm{ML}$

3) $\mathrm{KT}$

4) $\mathrm{DD}$

5) $\mathrm{SA}$

6) $\mathrm{SE}$

7) $\mathrm{CF}$

8) JS

9) $\mathrm{AH}$

10) SM

11) $\mathrm{CS}$

12) $\mathrm{AH}$

13) JW

M

70

61

92

M

55

51

51

48

AGE ATEND 
weeks as the study began.

Teachers. There was one master teacher for the infants/toddlers and one master teacher for the transition room. Each master teacher had a B.S. degree in either early childhood education or human development and a minimum of six years of experience as an early childhood educator. There was also one associate teacher per room. Each associate teacher had an A.A. degree in either early childhood education or human development and a minimum of six years of experience as an early childhood educator. There were two assistant teachers in each room as well. Assistant teachers had an A.A. in early childhood education or human development.

\section{Setting}

Quality Control. The center had adopted a number of policies to insure a high quality of care for those children who attend. In addition to the qualifications of the teachers, the ratio of children to caregivers was low. For the infants and toddlers it was $1: 3$, and for the transition room children it was 1:4. Caregivers for the infants were required to spend at least one day in the child's home and have several infant, parent, and caregiver meetings before the child was allowed to spend a whole day at the center. In at least one case, the teacher who provided primary care for a toddler (at the time of this study) had been introduced to the baby one week after birth. To insure stability of caregivers over time, the children changed rooms as a group and the caregivers for the infants and toddlers were assigned individually to specific children for two years.

Classrooms. As previously mentioned, the children under observation were in three different classrooms, the infant room, the toddler room, and the transition room. For the toddlers and transition children, observations were also made in a multi-purpose room. In addition, all children were filmed during outdoor play as well.

The infant room was subdivided into a changing room, a mealtime area, two adjoining play areas, and a sleeping room. All indoor observations were made in either 
the mealtime area or the play areas. The play areas were large enough so that infants had room to move around and had windows low enough for small children to see outside. In addition, low toy shelves allowed the small children access to toys. There was an assortment of colorful toys, mobiles, and pictures on the walls.

The toddler room was similarly divided with a changing room, kitchen area, and adjoining play area. There was an abundance of toys: dolls, blocks, cars, etc. There was also some climbing toys such as a small slide and climbing stairs.

The transition room was somewhat larger than the infant and toddler rooms. The main play area was subdivided into a reading area with a small couch facing a bookshelf containing a wide assortment of children's books. Behind the couch was a large doll house. In the adjacent play areas, there was a slide, and a table on which children often rolled cars on and used for other play activities. The areas were divided by low toy shelves. In addition, there was a mealtime area that was also used for structured activities such as painting and cooking.

All three of the classrooms had open-faced lockers (called cubby-holes or cubbies") for the children to store their personal belongings such as coats and a change of clothing.

The multi-purpose room was a large, open room that allowed the children to move around very freely. This room was used for more physically oriented play. As such, it contained play structures to climb on, very large inflatable balls ( 3 feet in diameter), and large mats.

The outdoor play yard was located behind the development center in a open, grassy area that bordered a wooded forest. The outdoor play yard was subdivided for the different age groups. For infants and toddlers, the play areas were adjoining to the classrooms and enclosed with a small fence. The infant and toddler areas were separated by a large gate that was often left open so that children had access to both areas during 
play times. The transition and preschool children shared a much larger area which consisted of two large climbing structures, a large sandbox, and two barns for the children to play in.

\section{Design and Observation Procedure}

There were four different measurement times over a span of six months beginning in late February and concluding in late August, 1994. The first time of measurement consisted of a cross-sectional study that included all 37 children whose parents provided consent (from 2-22-4 through 4-1-94).

Practical considerations required that the subject pool for the longitudinal study be limited. Because prosocial behaviors are typically low in frequency, a decision was made to observe fewer children in more depth, i.e., to increase the amount of time spent videotaping individual children. Therefore, an age criterion was established. The strategy was to select children within each age group whose age at the end of the study (Time 4) overlapped with the age of the next older group of children at the beginning of the study (Time 1). Table 2 shows the results of the age selection strategy and the 21 children who were included in the longitudinal study.

Prior to the actual data collection, the children were videotaped for approximately 5 hours. This allowed the children to become accustomed to being filmed and also allowed videotapers to establish taping strategies. The children were videotaped using a focal child technique, i.e., the camera followed a particular child as the child went about his/her activities and social interactions. As the focal child, he/ she was free to do whatever he / she chose (unless a teacher intervened) and the videotaping was undertaken as unobtrusively as possible.

At all measurement times, individual children were videotaped in three-minute intervals. There was a goal of 90 minutes of videotape on each child per measurement point. For each day of videotaping, a random list of the participating children was 
Table 2

Age in Weeks (and Gender) of Children Selected For Longitudinal Observation

INFANTS

\begin{tabular}{|c|c|c|c|c|c|c|c|c|}
\hline $\begin{array}{l}\text { Age at } \\
\text { Time } 1\end{array}$ & & $\begin{array}{l}\text { Age at } \\
\text { Time } 4\end{array}$ & $\begin{array}{l}\text { Age at } \\
\text { Time } 1\end{array}$ & & $\begin{array}{l}\text { Age at } \\
\text { Time } 4\end{array}$ & $\begin{array}{l}\text { Age at } \\
\text { Time } 1\end{array}$ & & $\begin{array}{l}\text { Age at } \\
\text { Time } 4\end{array}$ \\
\hline 27 & $\mathrm{AH}(\mathrm{F})$ & 51 & 73 & $V P(M)$ & 95 & 119 & $\mathrm{BF}(\mathrm{M})$ & 143 \\
\hline 33 & SM (F) & 57 & 77 & PK (F) & 100 & 125 & $\mathrm{JC}(\mathrm{M})$ & 148 \\
\hline 35 & $\mathrm{AH}(\mathrm{M})$ & 58 & 92 & $\mathrm{AL}(\mathrm{F})$ & 115 & 139 & $\mathrm{CS}(\mathrm{M})$ & 163 \\
\hline 34 & JS (M) & 59 & 97 & $\mathrm{KW}(\mathrm{F})$ & 120 & 150 & $\mathrm{KL}(\mathrm{F})$ & 174 \\
\hline 48 & SE (M) & 72 & 97 & $\mathrm{SD}(\mathrm{F})$ & 121 & 153 & CR (F) & 177 \\
\hline \multirow[t]{4}{*}{55} & $\mathrm{KT}(\mathrm{F})$ & 79 & 100 & $\mathrm{CS}(\mathrm{M})$ & 123 & 163 & CT (F) & 186 \\
\hline & & & 103 & $\mathrm{ZS}(\mathrm{M})$ & 126 & & & \\
\hline & & & 106 & $\mathrm{KM}(\mathrm{F})$ & 129 & & & \\
\hline & & & 109 & $\mathrm{AJ}(\mathrm{M})$ & 132 & & & \\
\hline
\end{tabular}


prepared. The children were videotaped in that order. If a child was unavailable for taping (absent, sleeping, or in a different room) he/she was put at the bottom of the list (if possible) and revisited at a later point in time. Care was taken to ensure that structured activities, free play, and mealtimes, described below, were sampled in proportion to the time that the child was actually engaged in each activity. Appendix A lists the total minutes each child was filmed as the focal child at each measurement point in which he / she participated. As described in Appendix A, the 37 children who participated in the cross-sectional study were each filmed for an average of 84 minutes with a range from 27 to 170 minutes. For the longitudinal study, 21 children were filmed for an average of 94 minutes at each of the three subsequent measurement points. The range for the longitudinal study was from 28 to 152 minutes of film.

In the original design of the study, it was intended to videotape the children evenly across all three of these different group activities ( 30 minutes of each activity). However, towards the end of the first measurement point it became apparent that this was not possible due to time restrictions. It was necessary to end the first measurement point so that there would be sufficient lag time before the second measurement point. It was not possible to obtain 30 minutes of each child at structured play, and in some cases, at mealtimes. This shortcoming was due to the fact that children spent more of their time engaging in free play than either structured play or meal times. Also, engaging in structured activities was the child's own choice and there were large individual differences in the amount of time children spent participating in structured activities.

However, it should be noted that children were videotaped for approximately equal amounts of time during mealtimes (although still below the original goal of 30 minutes). Because children spent approximately equal amounts of time eating, this indicated that the children were being videotaped evenly and it is believed that the amount of time individual children were captured participating in structured play 
activities was an accurate representation of how often they actually engaged in structured play.

\section{Development of Behavior Codes and Coder Training}

Four undergraduate and two graduate students comprised the initial research team. To develop an accurate coding scheme, this team was required to read the Hay and Rheingold (1983) chapter on early prosocial development. Subsequently, pilot observations were made on-site in which members of the research team were instructed to scan the room and locate children in social interactions, in particular, in prosocial interactions. The observations were written up as narrative reports that included what behaviors occurred, what was said, and what the social partner(s) did and said. In addition, the research team met for four hours a week. The narrative reports provided material for discussions and, together with the research literature reviewed earlier, became the basis for the observation code.

Currently, all the videotape footage of the children has been collected and six more students have joined the research team (three are undergraduates, three are postbacculaurete students). Until coding of actual videotaped data begins, the team meetings that continue four hours weekly serve as a forum for refining and differentiating the behavior codes and developing specific coding rules.

\section{Behavior Codes: Prosocial Behaviors}

The content of the target child's behavior was to be coded into the following categories (see Appendix B for the entire coding manual):

1. Rule Compliance- Child performs behaviors that are required or expected as rules of the center. In general, these rules involve cleaning up after self or other self care activities (e.g., putting toys away at designated times, washing hands before mealtimes, and cleaning up after mealtimes). This category also includes any compliance with a teacher's request not coded in other prosocial category. 
2. Performing the work of adults- Child performs tasks of adults in the child care setting that are similar to domestic tasks (e.g., folding laundry, wiping down tables, setting table, carrying food). These are tasks that are not considered to be the child's "duties", nor are they required by the rules of the center.

3. Helping- Child provides any form of task assistance that is not considered participation in the work of adults. This category includes attempts to alleviate another person's nonemotional needs, e.g., finding a lost object, retrieving a dropped object, or opening the door for another. In the planning stages of the code, it was intended to include an independent teaching category. However, preliminary observations of children in the current study indicated that teaching was a behavior that occurred rarely. For this reason, teaching is coded as a form of 'helping'.

4. Caregiving-Child displays nurturant acts toward dolls, animals, or other inanimate objects. This category includes feeding, grooming, bedding, positioning or transporting, caressing, or performing any other prosocial behavior towards an object or animal.

5. Affection- Child hugs, pats, kisses, or touches another in a positive manner.

6. Distress to distress- Child shows a negative emotion to another person's distress, including crying, sobbing, fretting, whimpering, or having a cryface.

7. Attention to distress- Child stops own activity and looks at or in direction of distressed person.

8. Comfort/concern for distressed-Child verbally or physically attempts to console, help, or intervene on behalf of distressed person. This category includes offering physical comfort, verbal comfort or sympathetic statements, verbal advice, or help to the distressed individual.

9. Pointing- Child extends arm and index finger toward a stimulus while looking at it, while making eye contact, or accompanied by a "sharing" verbalization (e.g., "Look 
at that").

10. Showing-Child holds up an object toward another person but does not relinquish control of the object.

11. Sharing- Child relinquishes to another an object that is in his/her current possession or use.

12. Assertive Problem Solving- In the current study, defending oneself nonaggressively (by using words) or pro-actively avoiding conflicts (by using words) is coded as assertive problem solving. This category is very similar to the 'actively resisting' category utilized by Fabes and Eisenberg (1992). To be coded as assertive problem solving, the target child uses a verbal statement designed to avoid or resolve conflicts. The verbal statement must be made by the target child to the person with whom the potential conflict exists or to a teacher when that individual is within earshot. Behavior Codes: Other Behaviors

In addition to coding the prosocial behaviors, the following transgressions will also be coded:

\section{Noncompliance-}

In the current study, preliminary observations by the research team indicated that skilled attempts at noncompliance (making excuses and negotiating) occurred very infrequently. Therefore, in the current study, only unskilled attempts at noncompliance will be coded. Kucyzinski and Kochanska (1990) differentiated unskilled attempts at noncompliance as either passive noncompliance or direct defiance. In the current study passive noncompliance is coded as noncompliance by omission (failing to comply to a request or prompt); direct defiance (and resistance to teacher requests) will be included in the commission noncompliance category.

Commission-- Child performs an observable noncompliant behavior i.e., removes objects from proper place, stands or walks on furniture, resists or defies 
teacher's request or prompt.

Omission-- This category includes failing to follow the rules of the center or to not comply with a caregiver's request within 10 seconds (Barkley, 1987).

2. Resource Violation-- Target child attempts to take away (grab) object or toy in another's physical possession or one that is clearly being used by another.

3. Physical Aggression- Child attempts or actually pushes, hits, kicks, bites, or spits at another child. This category also includes throwing an object in anger, regardless of accuracy, and physical impingement on another person (e.g., hard pats, obtrusive exploration of face or body (mainly for infants)).

In addition to coding the preceding behaviors, the following categories will be included to ensure that an exhaustive system is established:

1. Entry Bid-Child makes an obvious, focused attempt to gain attention with the intent to initiate a new social interaction. Also, failed attempts at initiating a new social interaction (the child's social partner rejects his / her entry bid) are coded. Entry bids must include looking at the social partner and either : a verbal request or invitation to play, a beckoning gesture, imitative actions, the initiation of parallel play, or any other codeable behavior.

2. Social Behavior- Child makes eye contact or purposeful physical contact, participates in a joint activity, engages in mutual behavioral responses (child A vocalizes, child B smiles or laughs), looks at another person while vocalizing or directing one's behavior toward him/her, or looks at a person while that person vocalizes or directs behavior toward the focal child. This category also includes lead/follow/imitating, smiling with eye contact, and participating in social games or play. This category is also coded whenever the target child is within three feet of another person.

3. Solitary-Solitary behavior will be coded if there is an absence of social behavior for a minimum of ten seconds. This category will also be coded if the target 
child or his/her social partner turn away such that their body orientation is not toward each other.

All behaviors will be recoded if the duration of the behavior is greater than 10 seconds (i.e., 40 seconds of solitary behavior is coded as four events).

In addition to the preceding child behaviors, the following teacher behavior will be coded:

1. Teacher Prompt- It is necessary to code teacher prompts in order to code compliance to or noncompliance with requests and commands made to the target child. A teacher prompt will consist of any suggestion, recommendation, command, or request made by a teacher to the target child or group of children which includes the target child.

In addition to coding the content or form of behaviors, the initiator of the behavior and to whom the behavior is directed will also be coded (with the exception of 'solitary' or 'social'). There are four mutually exclusive categories for the initiation of a coded behavior : self-initiated, peer-initiated, adult-initiated, or mutually-initiated/ undeterminable. There are also four mutually exclusive categories for whom the behavior is directed to: peer, adult, somebody, and nobody. A code of 'somebody' indicates that the child's behavior is directed toward someone out of camera range or the behavior is directed toward a symbolic representation of a person (a doll). A code of 'nobody' indicates that the social partner recipient of the child's behavior is undefined or the behavior is directed toward no one in particular. An example of a coded behavior that is directed to nobody would be a child pointing to an object he / she is looking at when there is no one else around.

Also to be coded is the group situation which specifies one of three possibilities: free play, structured play, or mealtime. Structured play will be defined as any play activity which is initiated by an adult caregiver who directly supervises and sometimes participates in the activity. Structured play involves limited resources such as clay, paint, 
chalk, sandboxes, cooking utensils, etc., which are controlled and distributed by the supervising caregiver. Children have the choice of participating in structured activities or may engage in free play. During free play, a child partakes in self-directed, self-chosen activities and is able to play with any of the available resources that are not reserved for structured play, mealtimes, or nap times. The group situation was coded by the camera person while filming.

\section{Coding Procedure}

Coding proceeded continuously across the three-minute observations. Behavioral events were coded in the natural sequence of their occurrence; coders noted the running time of each event on the tape (hour, minute, and second). When the editing and compilation of a reliability videotape were completed (to be described below), three members of the research team coded it. The three observers spent an average of 14 hours coding the entire 2.25 hours of videotape. Coding was done with paper-and-pencil; two of the three observers used coding sheets designed by a member of the research team, the third used notebook paper and then transferred the results to coding sheets. All three of the observers were post-bacculaurete students. Two were the newest members of the team and the third was not an original member of the research team.

\section{Reliability}

This study is an evaluation of current progress in the development of the coding system. Coding of actual data will begin only after it is established that all coders are trained well enough to be highly reliable on the training material (Cohen's kappa $>.69$; Cohen, 1960)

As part of the larger study, this reliability study was conducted to assess the readiness of the coding scheme. Due to the large number of behaviors observed and the complexities involved with combining an event oriented and interval oriented coding strategy, it was decided that a preliminary reliability study was necessary to determine 
the major sources of coding discrepancies and to help set the training agenda.

Thus, the goals of this reliability study were twofold: to assess the readiness of the coding system and the training manual and to locate any discrepancies in coding between observers that may be overcome by more training or by making changes or additions to the coding manual.

Procedure for Reliability Study

In order to accomplish these objectives a reliability videotape was constructed. This videotape was assembled with 3 goals: (1) to capture as many different behaviors as possible over the entire age range of the children who participated in the research and (2) to include all three types of group situations in which the children were observed (free play, structured play, and mealtimes) and (3) to keep the range of prosocial behaviors as broad as possible.

These goals were accomplished through a process which began with all members of the research team reviewing different videotapes. They noted any codeable behaviors that occurred, the child who performed the behavior, and the activity in which he / she was engaged at the time the behavior occurred. From these notes and from information logged in by the camera person while videotaping, 42 three-minute intervals were chosen. Twenty-one intervals from the first and fourth measurement points were selected.

The intervals chosen were evenly distributed over the three different classrooms. In other words, there were fourteen intervals chosen from each classroom, seven from the first measurement point and seven from the fourth measurement point. This strategy dictated that seven intervals were of the infants during measurement point one (the youngest children who participated) and seven intervals were from the transition class during the final measurement point (the oldest children who participated). Thus, the entire age range was covered.

For toddlers and transitioners, the proportion of time videotaped during free play, 
mealtimes, and structured play was roughly $4: 2: 1$. For infants, who do not have a structured play choice, the proportion of free play to mealtimes was 5:2. In constructing the reliability tape, these were the absolute number of intervals chosen by activity (i.e., for toddlers and transitioners, there were 4 free play segments, 2 mealtime segments, and 1 structured activity interval chosen from measurement points one and four). For the infants, 5 of the seven intervals for each measurement point were of free play and 2 were of mealtimes.

\section{Expectations}

Expectations were that there would be no significant differences between observers in their coding of the reliability tape. This would indicate that all three observers were equally trained and proficient at coding the childrens' behavior. In addition, it was expected that the highest levels of reliability would be achieved in observation of infants because their behaviors would not be as complex as those exhibited by the older children. Also, it was suspected that free play, when the children are moving around freely, would be the most difficult group activity to code and therefore the least reliable. For structured play and mealtimes, the range of codeable behaviors exhibited was expected to be more restricted. In addition, for mealtimes and structured activities the children were expected to be more likely to stand still or remain in one place which was would also lead to higher reliability because no poor camera angles would occur.

\section{RESULTS}

The experience of coding the reliability tape by the three members of the research team was a very valuable component of this research project. They reported that many times, while coding, they had successfully used the coding manual when they had a question about how to code a particular behavior. In addition, they reported that there was considerable ambiguity in the code regarding the 'initiation' and 'direction' components. At subsequent research meetings, additional decision rules regarding the 
initiation component of some behavior codes were developed and modifications were made to the 'initiation' and 'direction' categories.

Reliability. Inter-observer reliabilities were calculated using the formula for kappa developed by Cohen (1960). Cohen's kappa was chosen as the measure of inter-observer reliability for this study because it is both the conventional measure of reliability in observational prosocial development research and because it adjusts for observer agreements that have a high probability of being due to chance. Also, observed percent agreement was included in all analyses because kappa is known to be affected by the complexity of the interaction observed in addition to code-specific unreliabilities. In essence, kappa's estimate for chance agreement in a code (which is removed from the observed agreement between coders) is affected by the number of different behavioral categories that one registered in a given observational episode.

Because the observers had reported ambiguity in the initiation and direction components of the code and changes to the code had already been planned, it was decided to calculate the kappas using both the entire coding system (behavior-initiation-direction) and also with the under-trained categories (initiation and direction) eliminated. It was expected that kappas for the entire code would be significantly smaller than kappas calculated when the initiation and direction were removed.

Kappas were calculated for each of the 42 three-minute intervals. For every interval, the codes from each observer were compared to the codes from both of the other observers. This resulted in two kappa values for each observer per interval. Table 3 reports the average kappa values, the percent agreement, and the chance percentage for each observer by age group of the children observed. Values are reported for both the entire coding system and the behavior portion only. Table 4 reports these values for each observer by group activity. An examination of Tables 3 and 4 revealed that the kappa values associated with the behavior categories alone were consistently higher than those 
Table 3

Prosocial Behaviors

Agreement Between Observers Across Age Groups

\begin{tabular}{lccc} 
& \multicolumn{3}{c}{ OBSERVER } \\
& 1 & 2 & 3 \\
\hline INFANTS & & & \\
ENTIRE CODING SYSTEM & & & 0.74 \\
OBSERVED AGREEMENT & 0.76 & 0.51 & 0.50 \\
PERCENTAGE CHANCE & 0.49 & $\mathbf{0 . 5 3}$ & $\mathbf{0 . 4 9}$ \\
KAPPA & $\mathbf{0 . 4 9}$ & & \\
BEHAVIOR CATEGORY ONLY & & & 0.81 \\
OBSERVED AGREEMENT & 0.80 & 0.81 & 0.51 \\
PERCENTAGE CHANCE & 0.48 & 0.51 & $\mathbf{0 . 6 2}$ \\
KAPPA & $\mathbf{0 . 5 8}$ & $\mathbf{0 . 6 2}$ & \\
\hline
\end{tabular}

TODDLERS

ENTIRE CODING SYSTEM

$\begin{array}{llll}\text { OBSERVED AGREEMENT } & 0.70 & 0.71 & 0.71 \\ \text { PERCENTAGE CHANCE } & 0.44 & 0.46 & 0.46 \\ \text { KAPPA } & \mathbf{0 . 5 1} & \mathbf{0 . 4 7} & \mathbf{0 . 5 0}\end{array}$

BEHAVIOR CATEGORY ONLY OBSERVED AGREEMENT PERCENTAGE CHANCE

$\begin{array}{lll}0.77 & 0.79 & 0.80 \\ 0.46 & 0.47 & 0.48 \\ \mathbf{0 . 6 0} & \mathbf{0 . 5 9} & \mathbf{0 . 6 2}\end{array}$

KAPPA

0.59

0.62

TRANSITIONERS

ENTIRE CODING SYSTEM

$\begin{array}{llll}\text { OBSERVED AGREEMENT } & 0.60 & 0.66 & 0.65\end{array}$

PERCENTAGE CHANCE $\quad 0.35 \quad 0.39 \quad 0.39$

$\begin{array}{llll}\text { KAPPA } & 0.41 & 0.47 & 0.45\end{array}$

BEHAVIOR CATEGORY ONLY OBSERVED AGREEMENT PERCENTAGE CHANCE

$\begin{array}{lll}0.73 & 0.75 & 0.76 \\ 0.40 & 0.42 & 0.42 \\ \mathbf{0 . 5 8} & \mathbf{0 . 6 0} & \mathbf{0 . 6 1}\end{array}$

0.60

0.61 
Table 4

Agreement Between Observers Across Group Situations

\begin{tabular}{|c|c|c|c|}
\hline & & SERV & \\
\hline & 1 & 2 & 3 \\
\hline FREE PLAY & & & \\
\hline ENTIRE CODING SYSTEM & & & \\
\hline OBSERVED AGREEMENT & 0.69 & 0.71 & 0.70 \\
\hline PERCENTAGE CHANCE & 0.42 & 0.44 & 0.45 \\
\hline KAPPA & 0.46 & 0.49 & 0.47 \\
\hline BEHAVIOR CATEGORY ONLY & & & \\
\hline OBSERVED AGREEMENT & 0.75 & 0.76 & 0.77 \\
\hline PERCENTAGE CHANCE & 0.44 & 0.46 & 0.47 \\
\hline KAPPA & 0.55 & 0.59 & 0.58 \\
\hline STRUCTURED PLAY & & & \\
\hline ENTIRE CODING SYSTEM & & & \\
\hline OBSERVED AGREEMENT & 0.75 & 0.81 & 0.81 \\
\hline PERCENTAGE CHANCE & 0.56 & 0.59 & 0.59 \\
\hline KAPPA & 0.49 & 0.51 & 0.58 \\
\hline BEHAVIOR CATEGORY ONLY & & & \\
\hline OBSERVED AGREEMENT & 0.85 & 0.87 & 0.87 \\
\hline PERCENTAGE CHANCE & 0.60 & 0.61 & 0.62 \\
\hline KAPPA & 0.64 & 0.62 & 0.68 \\
\hline MEALTIME & & & \\
\hline ENTIRE CODING SYSTEM & & & \\
\hline OBSERVED AGREEMENT & 0.64 & 0.68 & 0.65 \\
\hline PERCENTAGE CHANCE & 0.37 & 0.40 & 0.39 \\
\hline KAPPA & 0.45 & 0.48 & 0.44 \\
\hline BEHAVIOR CATEGORY ONLY & & & \\
\hline OBSERVED AGREEMENT & 0.75 & 0.78 & 0.79 \\
\hline PERCENTAGE CHANCE & 0.38 & 0.41 & 0.40 \\
\hline KAPPA & 0.61 & 0.65 & 0.67 \\
\hline
\end{tabular}


from the entire coding system. In addition, differences between observers for kappa values and observed agreements were small. For example, the range of kappa values across observers for intervals focused on infants was $(0.58 \ldots 0.62)$ when the behavior categories alone were considered. This consistent pattern suggested that all three observers had been equally trained.

Repeated measures analyses of variance (ANOVA's) were performed to determine whether there were significant reliability differences between observers, across the different age groups of the children, or across observations of the children engaged in different group activities. All analyses were carried out using SYSTAT software for IBM compatible computers. All analyses used kappa values and percent agreement obtained when the entire coding system was considered and also when the behavior categories alone were compared.

The first step in the analyses was to average the kappas and percent agreements for each interval. Previously, two kappa values (and two percent agreements) were obtained for each observer for every one of the 42 intervals. These two values were averaged so that there was one kappa (and one percent agreement value) for each observer for every interval. It was assumed that an average of an observer's reliabilities with the 2 other observers would be the best estimate of his or her 'true' reliability. In addition, if the same child was the focal child in more than one interval, in each interval in which he or she was the focal child, the kappa values and percent agreements were averaged. For these analyses, there was one kappa and one percent agreement value for each child per observer.

An alpha level of .05 was used for all statistical tests. The first analyses performed were repeated measures ANOVA's with three factors: age (three groups), kind of reliability ( 2 kinds, the entire coding system or the behavior categories only), and observing person (3). Necessarily, observed percent agreement was significantly higher 
than the kappa values. Also, as expected, the kappa values and observed percentages associated with the entire coding scheme were significantly lower than those based on the behavior categories alone (i.e., excluding the initiation and direction categories).

When the entire code was considered, there was no difference across observers, $(\mathrm{F}$ $(1,22)=1.17, \mathrm{p}>.05)$. As expected, however, there was a significant main effect for age, $(\underline{F}(2,22)=3.93, \underline{p}<.05)$. This age difference was not present when only the behavior categories were considered, $(\underline{\mathrm{F}}(2,22)=.981, \mathrm{p}>.05)$. In addition, there were no significant interactions between observer, kind of reliability, and age.

To follow up on the significant age difference, kappas and percent agreements were tested separately across the different age groups (for the entire code) in a univariate analysis. For the kappas, the age difference was not significant, $(\underline{F}(2,22)=1.83, p>$ .05 ). Only the percent agreement scores differed significantly across the age groups of the children, $(\underline{E}(2,22)=3.89, \underline{p}<.05)$.

Testing the reliability across the different group situations proved to be more demanding. Because the infants were not presented with structured play choices, age could not be included in an analysis of group situation. Hence, for this analysis, it was decided to average kappa values, not only across individual children, but also across group situation (i.e., if a child had been observed more than once in the same group situation, those kappas and percent agreements were averaged). Nevertheless, it was still necessary to estimate some kappa values ( 8 out of 21 ) to increase the low number of children who had been observed in all three group situations. As estimates, the mean scores of those other children of the respective age group who had been observed in those situations were taken. Four of the estimated values were for the transitioners at free play and four were for toddlers at structured play.

A repeated measures ANOVA was performed which compared the two kinds of kappa values across the three group situations. The kappas tested were based on both the 
entire coding system and also on the behavior categories only. As expected, the kappas based on the behavior categories only were higher than those associated with the entire coding system. However, there were no differences across group situations, $(\underline{F}(2,12)=$ $.105, \mathrm{p}>.05)$.

In a similar fashion, all the values for observed agreement between coders were compared across the three group situations in a repeated measures ANOVA. Again, the values based on just the behavior categories were higher than those based on the entire coding system. In addition, there were significant differences between the observed agreement and group situation, $\mathrm{F}(2,12)=4.12, \mathrm{p}<.05$. Mealtime appeared to be lower than the other two situations.

In a second step, a confusion matrix of observer's disagreements was constructed. It was a $20 \times 20$ matrix with all the behavior categories along both axes. The initiation and direction components of the coding system were not considered. To assemble the confusion matrix, each coder's entries were aligned with each of the other observers' entries. The corresponding entries were tallied in the confusion matrix. As a result, each coder's entries were counted twice in the confusion matrix.

The confusion matrix was designed to single out specific categories that were coded unreliably. It illuminated two problem areas. One problem was with the pointing and pointing with joint attention categories. Sixty percent of the pointing events coded did not match other observers' codes. In the pointing with joint attention category, fortysix percent of the entries were not matches. Based on the fact that these categories were not coded with acceptable reliability and there were conceptual problems in differentiating the two categories, they were collapsed into one. In addition, it was discovered that two categories that consisted primarily of verbalizations, assertive problem solving and teacher prompts were not coded very well. Twenty-two percent of the assertive problem solving codes matched with another observers' code while fifty-two 
percent of the teacher prompts coded were a match. Modifications were made which broadened these two categories to include a wider variety of verbal statements.

\section{Planned Analyses of Cross-Sectional Data}

The first step in the analysis of the behavioral data will be to determine the percentage of children at each age group who were observed performing each behavior. Also, individual profiles of the children's behavioral tendencies will be examined. A profile will be compiled for each child who participates in the study. These profiles will be presented as histograms plotting behavioral frequencies for each individual behavior category. It is hoped that these profiles will reveal patterns across children in the differing forms of prosocial behaviors that are performed. In addition, inter-correlations of the twenty behavior categories will be computed. The inter-correlations among variables will be inspected for clustering of behaviors that have theoretical relevance.

For the remaining statistical procedures, the dependent variables will be converted from the absolute number of events to events per minute; arc-sine transformations of the proportions may be used in order to eliminate inter-dependency among the rates. Two preliminary multivariate analyses of variance (MANOVAs) will be performed. Both of these analyses will consider all of the dependent variables but only one independent variable each.

This step of the data analysis is designed to justify the elimination of two independent variables that are of lesser interest. The first independent variable tested in this manner will be gender. Gender has been found to be an insignificant factor in much of the pertinent research on very young children so it is predicted that no gender differences will be found. The second independent variable tested will be the group situation. This variable was included in the observational scheme as a precautionary measure. It is suspected that mealtime prosocial behavioral frequencies may be different than at other times. 
In addition, some members of the research team indicated that the amount of structure associated with play time influenced the number of prosocial behaviors that occurred. Much of the previous research on prosocial behaviors has taken place in contrived laboratory situations; therefore, a group situation variable was unnecessary in those studies. The elimination of these variables in the present study would aid in the interpretation of subsequent analyses and enhance the statistical power of the study. For this reason, justification for the elimination of the group situation variable will be attempted.

Following these preliminary analyses, the remaining independent variable (age) and the dependent variables (i.e., coded behaviors, initiation, and direction) will be analyzed, again using a MANOVA procedure (the gender or group situation variables will be included in this analysis only if the significance of the influence exerted has been demonstrated). If necessary, following the MANOVA, discriminant functions for each of the independent variables will be obtained. These discriminant functions will describe the relative influence that the independent variables exert on the dependent measures.

\section{Expected Results of Cross-Sectional Study}

As previously mentioned, the effect of gender is expected to be insignificant. For the group situation, the lack of an empirically justified alternative hypothesis results in the prediction of the null hypothesis. Age is expected to have positive main effects on prosocial behavior frequencies for all behavior categories with the exception of affection, distress to distress, and possibly attention to distress. It is also suspected that the discriminant functions will reveal that age is the strongest influence on prosocial behavioral tendencies. The individual behavior profiles and inter-correlations are expected to show that certain prosocial behaviors tend to occur together. For instance, it is suspected that young children who show a higher frequency of pointing may also engage in more showing and sharing behaviors. 
It is also expected that there will be age differences found in the frequency of resource violations and physical aggression. In addition, it is expected that resource violations will occur more often than physical aggression.

\section{DISCUSSION}

\section{Discussion of Reliability Study Results}

From the results of the reliability study, there are many positive signs that the coding scheme is trainable and that with additional training and slight modifications, acceptable levels of reliability will be achieved. The primary evidence for this assertion is that there were no significant differences found between observers. This indicates that all three observers were equally well trained.

In addition, most of the training prior to the reliability study was aimed at identifying and differentiating the behavior codes and relatively little time was spent training observers to identify the initiation and direction of those behaviors. Results showed that observers coded the behaviors more reliably when they were not specifying initiation and direction. There were no significant differences in coding the behavioral categories for which training had been rigorous. Also, the coders stated unequivocally that they had used the training manual. These factors indicate that observer training and the coding manual are effective tools and that with further refinement, observers can achieve reliability.

As previously mentioned, the initiation and direction components of the code were revised soon after the observers finished coding the reliability tape. The significant difference that was found indicating that mealtimes were coded less reliably than any other group situation was attributed to the fact that the coding manual did not specify to whom compliance was directed. The mealtime intervals that were coded included many instances when children were putting their eating utensils away and throwing away their trash. At subsequent research meetings, it was decided that the direction of these types of 
self-initiated compliant behaviors would be coded as Nobody.

In addition, many small changes were made to the coding manual as a result of comparing the observers' coding of the tape. For instance, information was added to reiterate the fact that any prosocial behavior directed towards an individual in distress is to be coded as comfort / concern for distress. Another addition was to mandate that any instance of performing the work of adults was to be necessarily directed toward an adult. As previously noted, due to a lack of reliability in coding the categories of pointing and pointing with joint attention, these two categories were collapsed into one.

Through the inspection of a significant difference that was found, much was learned about the function of the formula for Cohen's kappa. The significant difference found was an age difference that indicated that infants' behaviors were more reliably coded than the older children's, based on observed percentages when the entire coding system was compared. In other words, the behavior of infants was easier to code. This significant difference was not found when the kappas were tested. This leads one to believe that the formula for Cohen's kappa compensates for the difficulty of the interval that was coded. In the formula for Cohen's kappa, the percentage chance term (or expected frequency of agreement term) adjusts the kappa value based on the relative frequency of the different codes that were coded in any given interval. For intervals that were easier to code (i.e., consisted of a fewer number of different codes) the percentage chance terms were higher, which always results in lower kappa values.

The age difference was only found when the entire coding system (initiation behavior - direction) was compared. This indicates that initiation and direction of the older children was especially more difficult to code. This can be expected as the behavior of infants is less complex and takes longer to unfold which makes it easier for coders to observe.

Upon completion of the reliability study, the training agenda was set. There were 
a number of aspects of the coding system that needed to be refined. Some specific behavior categories were known to be sources or unreliability based on the reports from the three observers or revealed by the confusion matrix. These behavior categories included entry bids, assertive problem solving, teacher prompts, pointing and pointing with joint attention, and also the initiation and direction components of the code. It was decided to refine these behavior categories by having the research team code the reliability tape as a group. The reliability tape and group consensus of the corresponding coding entries will serve as training material for future coders.

\section{Developmental Implications and Future Directions for Code Refinements.}

During the collection of the videotapes, the author spent an average of 15 hours per week for sixteen weeks observing and filming the children. From this experience a number of hypotheses emerged regarding the behavior categories that may be unique to the current setting and testable through the coding system. These hypotheses could be explored through an analysis of the data from the cross-sectional study.

Social and Solitary. With the present coding scheme it is suspected that the social category will not necessarily reflect sociability. In other words, children with a higher number of social codes may not be the most social children. As a default category, social will be coded very frequently. To be coded as social, a child must be within three feet of another person. In this relatively crowded setting, this occurs quite often, which may diminish the variance between children for this category. However, due to the more stringent criteria for the coding of solitary, a higher frequency of solitary codes may be indicative of an alternative developmental trajectory.

It would seem reasonable to assume that children who are most often solitary engage in prosocial behavior relatively infrequently which would be reflected in lower frequencies in the prosocial behavior categories. In this setting, a child who is solitary significantly more often than his or her peers may be doing so by choice because he or 
she feels uncomfortable interacting socially (especially for toddlers and transitioners). Another possibility is that the solitary child may wish to interact but does not know how to initiate a social interaction in an appropriate manner. Again, this mainly applies to the toddlers and transitioners who are mobile and can move around freely.

This idea, that some solitary children do not wish to interact and others would like to interact but haven't developed strategies for initiating social interactions, may be testable through the current study. This would be accomplished by examining whether children found to be solitary more often also engage in other-initiated behaviors more often. If it is the case that a solitary child readily engages in other-initiated behaviors, one may argue that this child has the desire to interact socially but needs guidance to determine effective methods of initiating social interactions. If, on the other hand, a solitary child engages in self-initiated behaviors just as often as other-initiated behaviors, solitary behavior may reflect a lack of desire to interact. Presumably, these different patterns of interaction would reflect differences in temperament that may turn out to be stable and coherent over time.

Entry bid. One of the more interesting behavior categories in the current study is the entry bid category. One of the primary reasons for coding entry bids in the current study is the hope that further research will be carried out that examines the response of the social partner to the various types of entry bids that were made. This would provide empirical evidence to address the question of whether children who show a higher frequency of prosocial behavior also positively respond to the entry bids made by their peers more often.

Coding entry bids proved to be a very difficult task, especially if the entry bid did not incorporate either verbal invitations or some other coded behavior, such as sharing a toy to start a new social interaction. The difficult-to-score entry bids typically involved the initiation of parallel play or imitative actions. Very often it was difficult to note 
exactly when these entry bids occurred. For entry bids that involved the initiation of imitative actions, it was also difficult to determine if the child's intent was to interact with another as opposed to partake in an entertaining activity by oneself. Similarly, with parallel play, in some cases it was not possible to determine if the child's intent was to acquire an attractive resource or to engage another socially.

In general, childrens' entry bids could be classified into three very broad categories (prosocial, neutral, or anti-social). A prosocial entry bid may consist of sharing or showing a toy to start a new interaction while looking and smiling at the social partner. A neutral entry bid would include joining in an another's activity but with minimal interaction with the other person (i.e., looking at another while joining in a structured activity). Anti-social entry bids typically involved taking or grabbing another's toy. Individual children were observed to utilize these three types of entry bids in unequal proportion (i.e., some childrens' entry bids are predominantly prosocial while other children tried many different ways to start social interactions).

In the current study, children were observed to make very prosocial entry bids that included smiling, sharing or showing possessions (toys), and affectionate behavior. When observed in very young infants, it is difficult to resist the urge to classify these children as particularly prosocial. One may argue that in the current setting resources for the children are so abundant that the cost for sharing is very low. In addition, teachers and caregivers are active in their attempts to encourage prosocial behavior. Therefore, prosocial entry bids in the current setting may not be indicative of a stable prosocial personal style of interacting.

However, Hay and her colleagues (Hay et al., 1991) argue that the cost of sharing does not exert an influence until the second year of life. Also, despite efforts by the teachers to encourage prosocial behavior as a general rule, it has been noted by the esearch team that individual prosocial behaviors are not directly reinforced very often, 
either verbally or tangibly. A longitudinal study with a span of more than six months would be necessary to determine if children who make especially prosocial entry bids as infants and toddlers are more prosocial as they grow older. The current study is likely to provide the rationale to make the assertion that there are individual differences in the style of initiating new social interactions.

Most of the neutral entry bids included the initiation of parallel play and imitative actions. In addition to being difficult to code, determining the implication of these entry bids for prosocial development is impossible at the present time. Many times, neutral entry bids were made to a group and not to a specific other. Some of the most difficult to score entry bids included initiating a parallel activity such as running in circles around the room, hopping on one leg, or jumping up and down on a mattress. These type of entry bids seem to be more a result of the child's activity level than a desire to interact socially.

Although there were no children in this study who were suspected by the research team to make significantly more anti-social entry bids than the average child, we observed a number of these types of entry bids which include physical aggression and resource violations. In the current setting, the most common type of anti-social entry bids observed were resource violations. This is in accordance with prior research. From observations, it was clear that other children are aware of inappropriate styles for making social play entry bids. In one case, two recipients of an anti-social entry bid were observed to back off, and then approach the child who had made the anti-social entry bid in what looked like an attempt to antagonize the child. Based on these observations, it is suspected that the ability to make acceptable social play entry bids is a very important skill for success in school settings.

Some children who participated in this research were highly social and were involved in a wide variety and range of social interactions. These highly social children made entry bids that were both prosocial and anti-social. These children seemingly had a 
high motivation to interact socially and tried every method possible to enter into a social interaction. For these children, teacher interventions and modeling of prosocial entry bids would seem to be especially important. The goal would be to eliminate the child's tendency to start an interaction in an anti-social behavior. In addition, teachers who encourage other children not to allow themselves to be victimized by an anti-social entry bid would be particularly valuable to a child who uses a mixed bag of entry bids to attain social interaction. Having his or her anti-social entry bids resisted or rejected would seem to be paramount to a learning how to interact positively.

Assertive problem solving. Another behavior that was coded in the current study was assertive problem solving. This category included just about any attempt by the target child to avoid or diffuse conflict through the use of words. This category would be even more interesting if there were a comparison study involving two different child care centers. Ideally, the study could relate the frequency of assertive problem solving to the overall rate of prosocial and anti-social behaviors in the two centers. It is obvious that the teachers in the current study believe that the use of words to avoid and resolve conflicts is a valuable skill. Thus, a high frequency of adult-initiated assertive problem solving events is expected since teachers were continually encouraging children to "use your words" and to "deliver messages" to their peers. The current study may shed light on whether these teacher exhortations are internalized and become a part of the child's own behavioral repertoire. This would be determined by an examination of the changing relative frequencies of adult-initiated assertive problem solving and self-initiated assertive problem solving. A child who is internalizing this interfactional style may, over time, engage in more and more self-initiated assertive problem solving thus eliminating the necessity for adult initiation of the behavior.

Pointing, showing, and sharing. With regards to the pointing category, independent observers both within the research team and at the center indicated that 
children's first pointing behaviors were done with the intent of sharing experience and were not instrumental acts designed to benefit the child. During the study, two children in particular were observed at the age when pointing as a social gesture first appears. In both cases, it was judged by the author that children were pointing in order to share experience and not as a modification of reaching behavior designed to acquire an object. However, this is not to say that in all children pointing is initially a sharing behavior. In fact, many infants were observed to point when no one else was around. Pointing, it seems, indicates that a child has learned a method for directing someone's attention. Perhaps in some situations children point to direct their own attention. Whether or not pointing is an instrumental act or a sharing behavior would seem dependent on the context, the circumstances, and the child's own temperament.

With regards to the prosocial behaviors of sharing and showing, there were a number of characteristics of the current setting that increased the frequency of these behaviors.

One obvious characteristic of the child development center that influenced the frequency of showing and sharing was the number of resources available to the children. There were many interesting toys available to the children which presumably increased the frequency of both sharing and showing. Toys such as two-seated tricycles encouraged sharing among the children. Also, teachers frequently suggested to the children that they share toys and take turns.

In addition, there were daily activities for the children which many times resulted in a final "product" for the children (e.g., drawings, necklaces, paintings) which was naturally conducive to showing behaviors. It is expected that all the children (with the exception of the youngest infant) who participated in the study were captured on film showing and sharing objects with others. Many times these behaviors seemingly had a prosocial intent. However, sharing as an instrumental act (e.g., a child gives someone an 
object to hold for him or her) was indistinguishable from sharing as a prosocial behavior if only the form of the behavior was considered. In other words, by observing only the focal child's behavior, it is not possible to differentiate the instrumental from the prosocial form of the behavior. A separate study that examined sharing behaviors and other contextual variables such as the social partner's behavior would be necessary to distinguish between instrumental and prosocial sharing. Indeed, were it possible, it would be ideal to differentiate all of those behaviors that look similar in form to prosocial behaviors but actually involve egotistical intent. In the current research, this would involve examining fewer behaviors in more depth.

Helping and performing the work of adults. There were two types of helping behaviors coded in the current study: helping and performing the work of adults. In refining the coding manual, many times it was difficult to distinguish between these two behavior categories. Although there is a precedent in the research literature to consider performing the work of adults a separate behavioral category, in the current study it was necessary to designate certain tasks as the "work of adults" without a strong conceptual basis for doing so. In the absence of other data from natural settings or other longitudinal data, at this time it is unclear if it is worthwhile to distinguish between these types of helping behavior.

In the current study children have been observed to perform a variety of helping behaviors: picking up dropped objects, helping to push a tricycle uphill, opening a door for a teacher, wiping down tables, pushing a non-electric carpet sweeper, folding laundry, etc. It is the assertion of the author that, in many cases, children do not distinguish between work and play. When engaging in these behaviors, they are merely partaking in an activity that is interesting to them. This is especially true when the helping behavior is an activity (such as pushing the sweeper, or wiping down tables) which utilize objects that may be novel or stimulating to the children. Also, many times these activities 
involve interacting with a teacher which may be the child's primary goal. Although it is impossible to observe intent and motivation, many times the teacher offered praise and thanks for this type of helping (primarily coded in the 'performing the work of adults' category). Although the teacher is benefiting from the child's help in these situations, completing the task without the child's help would be simple. In comparison to the benefit a peer receives when he / she is the recipient of helping behaviors, it would appear that peers who are the recipient of another child's helping behavior benefit more than teachers. Children who were recipients of other children's helping behavior did not express thanks and were never observed by the author to offer praise. In light of these observations, it would appear that the most prosocial children would be identified by a higher frequency of self-initiated helping behaviors directed towards a peer. This idea can be examined the current study. If it is true that the most prosocial children engage in more self-initiated helping behaviors directed towards a peer, then the most telling aspect of a child's helping behavior is not the exact form of the behavior (i.e., whether it is sweeping the floor, helping to find a lost object) but who initiates it and to whom it is directed.

Caregiving. In prior research, there were no gender differences found in the frequency of young children's caregiving activities (i.e., engaging in nurturant activities directed toward dolls or stuffed animals). In the current setting, there was an abundance of toys and stuffed animals and also of caregiving "props" such as cribs, carriages, doll clothes, and baby blankets. In addition, there was even a structured activity the teachers named "washing babies" which involved a water table, soap, and anatomically correct dolls. Both boys and girls were observed to engage in these activities. One unique aspect of the current study (as compared to the one previous study focused on caregiving) is the collection of duration data. The coding scheme dictates that the child's behavior is coded every ten seconds. This permits an examination, not only of how many times the children 
engaged in caregiving activities, but also of how long each caregiving activity was sustained. With regards to the caregiving category, age differences are expected to exist, with infants engaging in this activity significantly less (both in terms of events and duration). The toddlers and transitioners appeared to caregive with similar frequency. However, it may be the case (in the opinion of the author) that a gender difference will be found in the amount of time spent caregiving. This gender difference is suspected to indicate that girls engage in caregiving episodes that are sustained longer than boys' episodes of caregiving.

Affection. With regards to the affection category, boys and girls were observed to engage in affectionate behavior that ranged from gentle pats to hugs and kisses. There was considerable difficulty in determining how to code the duration of affectionate behaviors like sitting in a teacher's lap or holding a teachers hand in terms of duration. The research team decided to code these behaviors once, when they initially occurred, but not to code prolonged episodes of lap sitting or hand holding as affection unless the child did something that was consistent with the affection category. It is not expected that there will be gender differences found in the affection category; however, there is expected to be age differences in the frequency of self-initiated affection with the infants performing these behaviors significantly less than the two older groups of children.

Responsivity to distress. Responsivity to distress has been researched in greater depth than any of the other prosocial behaviors. In the current setting, however, it is expected that the model described by Radke-Yarrow and Zahn-Waxler and their colleagues will not be replicated. Most of the research on which the Radke-Yarrow and Zahn-Waxler model was based involved maternal reports in a home setting. In the current setting there are more children than in a home setting and therefore, more incidents of distress. In fact, the infant room contained a baby monitor that allowed the teachers to listen to the infants who were napping, as they first fell asleep, and as they 
awoke. With the high number of children there were long periods of time when at least one child was distressed and crying, either in the main room or heard through the baby monitor. The research team unanimously agreed that habituation and desensitization caused the children to respond to distress less often than would be the case were the research conducted in a home setting where distress occurs less frequently. In addition, research in home settings often included the distress of a sibling or mother. In the child development center, the distress was always that of a peer (never the child's mother or sibling). Under these conditions, children responded to distress less often than was originally expected by the research team or than previous research would predict. Responding to distress with self distress was almost never observed in this study. Attention to distress is expected to be the most frequently observed response to distress. The author predicts that no age differences in the frequency of attention to distress will be found.

One interesting aspect of the attention to distress phenomena was an accompanying facial posture that was identified by the research team. This facial posture included a slightly agape mouth, eyes fully opened, and what appears to be an absence of expression. With regards to the comfort and concern to distress category, infants were observed to respond to the distress of another with comfort and concern. The author expects that there will be no age differences in the frequency of comfort and concern for the distress primarily due to the low frequency of this behavior. All in all, it is predicted that the current research will fail to replicate the major aspects of the responsivity to distress research that was reviewed. The failure to replicate is attributed to differences between home and child care settings.

Compliance and noncompliance. Two behavior categories for which establishing decision rules for coding proved to be most difficult were the compliance and noncompliance categories. In the reliability study, these categories were coded with 
relatively high reliability which reflected the time and effort that was spent developing the decision rules. These categories involved self-care activities and following rules of the center (or the failure to do so). These two categories may reflect the origins and development of behavioral self-regulation which is thought to be paramount in the development of moral behavior. For the most part, teachers were uniform in their enforcement of rules and in gaining compliance to their requests. The rules at the center are known to the children and revolve around two primary goals: not hurting others and the ability to care for and clean-up after oneself. When the coding is complete, it is expected that an interesting pattern will emerge involving episodes in which noncompliance and compliance are both coded within a small time span (many times more than once). This pattern will probably occur most often in the oldest age range and will reflect the development of childrens' noncompliance strategies and the diligence of teachers to enforce rules and their efforts to have children comply to requests. It is expected that there will be age differences in compliance and noncompliance rates. This is attributed to the fact that there are fewer expectations for the infants with regard to rules of the center (i.e., infants will not be asked to perform as many "chores" such as putting their own eating utensils away). This will limit the amount of both compliance and noncompliance opportunities. For the older children, there are more expectations and, consequently, more opportunities to comply (or not comply) to rules and requests. In addition, the oldest group of children will have more sophisticated means for not complying to rules and requests. Therefore, it is expected that the noncompliance rates will vary positively with the age group being observed.

Resource violations and physical aggression. Although this study is not focused on anti-social behavior, two forms of anti-social behavior have been included in the study: resource violations and physical aggression. In prior research, it has been documented that resource violations are the most common transgression committed by 
young children. It is suspected that the current study will lend support to this notion in that it is expected that the frequency of resource violations will be greater than the frequency of physical aggression. However, since the physical aggression category also includes aggression directed toward dolls and stuffed animals and aggressive behavior that is part of a game (playing "Lets Kick Each Other") the difference in frequency between resource violations and physical aggression may not be a great as originally expected.

With respect to resource violations, age differences are expected. Infants are expected to have lower rates of resource violations than the older groups. This is attributed to a lack of mobility and motor coordination on the part of the infants. However, the frequency of resource violations for the infants will be significantly greater than zero. Infants aren't yet aware of the fact that taking something from someone else is unacceptable behavior. As a result, infants may not hesitate to take another's resource, especially if it is food or a toy. With the older children, almost all the resource violations will involve toy struggles. Evidence of the high quality of care and the high level of caregiver aptitude in the current setting may be found by the frequency of adult-initiated assertive problem solving events that follow resource violations. This will reflect the teachers' suggestions to the children that there are alternative means for acquiring a desired toy, such as asking for a turn.

With regards to the physical aggression category, it is expected that there will be relatively low levels of physical aggression directed toward peers and very few directed towards adults. In fact, there may not be age differences in this category. If there is not, this is due to the fact that physical aggression is coded irrespective of intent. For the infants, who have a tendency to physically explore other people as if they were objects, the frequency of physical aggression may be higher than one might expect. However, the physical aggression of infants appears to be without malicious intent. With the 
unintentional physical aggression of infants' coupled with the fact that the teachers are adept at circumventing physical aggression in the older children, the age differences that would otherwise be expected may disappear.

Throughout the current study, there has been an accumulation of videotape that, when coded, will uphold the idea that a supportive environment is conducive to prosocial behaving and development. Children in the current study were filmed while performing the entire range of prosocial behaviors that have been identified in the research literature. The use of videotapes enables future researchers to examine the salient aspects in the environment, in the abilities and methods of teachers, and in the children themselves in order to learn more about how children develop and grow in terms of the social interactions in which they engage.

Future research is needed which utilizes the videotapes that have been collected in this study. The development of a coding system which is aimed at social partner responses to prosocial behaviors would compliment the current study nicely. Research could also be conducted which examines complex behavior processes such as compliance and noncompliance in greater detail. In addition, research is needed which distinguishes prosocial behaviors from behaviors which are identical in form to prosocial behaviors but have egotistical intentions. 


\section{Prosocial Behaviors \\ References}

Abramovitch, R., Corter, C., \& Lando, B. (1979). Sibling interaction in the home. Child Development, 50, 997-1003.

Abramovitch, R., Corter, C., Pepler, D., \& Stanhope, L. (1986). Sibling and peer interaction: A final follow-up and a comparison. Child Development, 57, 217229.

Barkley, R.A. (1987). Defiant children: A clinicians manual for parent training. New York and London: The Guilford Press.

Baron-Cohen, S. (1989). Joint-attention deficits in autism: Towards a cognitive analysis. Development and Psychopathology, 1, 185-189.

Bar-Tal, D., Raviv, A., \& Goldberg, M. (1982). Helping behavior among preschool children: An observational study. Child Development, 53, 396-402.

Cohen, J. (1960). A coefficient for agreement for nominal scales. Educational and Psychology Measurement, 20, 37-46.

Cummings, E.M., Hollenbeck, B., Iannotti, R., Radke-Yarrow, M., \& Zahn-Waxler, C. (1986). Early organization of altruism and aggression: Developmental patterns and individual differences. In C. Zahn-Waxler, E.M. Cummings, \& R. Iannotti (Eds.), Altruism and aggression: Biological and social origins (pp. 165-188). Cambridge: Cambridge University Press.

Dawkins, R., (1976). The selfish gene. Oxford: Oxford University Press.

Edwards, C.P. (1982). Moral development in comparative culture perspective. In D. Wagner and H. Stevenson (Eds.), Cultural perspectives on child development. (pp.112-136). San Francisco: W.H. Freeman.

Eisenberg, N. (1992). The caring child. London: Harvard University Press.

Eisenberg, N. \& Mussen, P.H. (1989). The roots of prosocial behavior in children. New York: Cambridge University Press. 
Eisenberg, N., Cameron, E., \& Tryon, K. (1985). Prosocial behavior in the preschool years: Methodological and conceptual Issues. In E. Staub, D. Bar-Tal, J. Karylowski, and J. Reykowski (Eds.), Development and maintenance of prosocial behavior: International perspectives on positive morality (pp. 101-115). New York \& London: Plenum Press.

Fabes, R.A., \& Eisenberg, N. (1992). Young children's coping with interpersonal anger. Child Development, $\underline{63}, 116-128$ ).

Forehand, R. (1977). Child noncompliance to parental requests: Behavioral analysis and treatment. In M. Hersen, R.M. Eisler, \& P.M. Miller (Eds.), Progress in behavior modification. (Vol. 5). New York: Academic Press.

Gralinski, J.H., \& Kopp, C.B. (1993). Everyday rules for behavior: Mothers' requests to young children. Developmental Psychology, 29(3), 573-584.

Harris, P. (1989). The autistic child's impaired conception of mental states. Development and Psychopathology, 1, 191-195.

Hay, D. (1979). Cooperative interactions and sharing between very young children and their parents. Developmental Psychology, 15(6), 647-653.

Hay, D., Caplan, M., Castle, J., \& Stimson, C. (1991). Does sharing become increasingly "rational" in the second year of life? Developmental Psychology, 27(6), 987-993.

Hay, D., Nash, A., \& Pedersen, J. (1981). Responses of six-month-olds to the distress of their peers. Child Development, 52, 1071-1075.

Hay, D., \& Rheingold, H. (1983). The early appearance of some valued social behaviors. In D.L. Bridgeman, (Ed.), The nature of prosocial development: Interdisciplinary theories and strategies (p. 73-94). New York: Academic Press.

Hobson, R. P. (1989). On sharing experience. Development and Psychopathology, 1 , 197-203.

Hoffman. M. (1975). Developmental synthesis of affect and cognition and its 
implications for altruistic motivation. Developmental Psychology, 5, 607-622.

Howes, C., Galluzo, \& Meyer. (1986). Codebook for developmental changes in responses to peers. Unpublished manuscript.

Howes, C., \& Farver, J. (1987). Toddler's response to the distress of their peers. Journal of Applied Developmental Psychology, $\underline{8}, 441-452$.

Howes, C., \& Olenick, M. (1986). Family and child care influences on toddler's compliance. Child Development, 57, 202-216.

Kochanska, G. (1993). Toward a synthesis of parental socialization and child temperament in early development of conscience. Child Development, 64 , $325-$ 347.

Kochanska, G. (1991). Socialization and temperament in the development of guilt and conscience. Child Development, 62, 1379-1392.

Kopp, C. (1982). Antecedents of self-regulation: A developmental perspective. Developmental Psychology, 18(2), 199-214.

Kuczynski, L., \& Kochanska, G. (1990). Development of children's noncompliance strategies from toddlerhood to age 5. Developmental Psychology, 26(3), 398-408.

Kuczynski, L., Kochanska, G., Radke-Yarrow, M., \& Girnius-Brown, O. (1987). A developmental interpretation of young children's noncompliance. Developmental Psychology, 23(6), 799-806.

Kurtines, W.M., \& Gewirtz, J.L. (Eds.), (1991). Handbook of moral behavior and development: Vol. 1. Theory. Hillsdale, New Jersey: Laurence Erlbaum Associates.

Leslie, A., \& Happe, F. (1989). Autism and ostensive communication: The relevance of metarepresentation. Development and Psychopathology, 1, 205-212.

Leung, E., \& Rheingold, H. (1981). Development of pointing as a social gesture. Developmental Psychology, 17(2), 215-220. 
Lickona, T. (1983). Raising good children: From birth through the teenage years. New York: Bantam Books.

Lickona, T. (1993). Educating for character: How our schools can teach respect and responsibility. New York: Bantam Books.

Marcus, R.F. (1986). Naturalistic observation of cooperation, helping, and sharing and their associations with empathy and affect. In C. Zahn-Waxler, E.M. Cummings, \& R. Iannotti (Eds.), Altruism and aggression; Biological and social origins (pp. 256-278). Cambridge: Cambridge University Press.

Mundy, P., \& Sigman, M. (1989). The theoretical implications of joint-attention deficits in autism. Development and Psvchopathology, 1, 173-183.

Patterson, G.R. (1982). Coercive family process. Eugene, Or: Castilia Press.

Patterson, G.R., \& Forgatch, M. (1987). Parents and adolescents: Living together. Eugene, Or: Castilia Press.

Pratt, M., Scribner, S., \& Cole, M. (1977). Children as teachers: Developmental studies of instructional communication. Child Development, $\underline{48}, 1475-1481$.

Radke-Yarrow, M., \& Zahn-Waxler, C., (1984). Roots, motives, and patterns in children's prosocial behavior. In E. Staub, D. Bar-Tal, J. Karylowski, \& J. Reykowski (Eds.), Development and maintenance of prosocial behavior: International perspectives on positive morality (pp.81-98). New York and London: Plenum Press.

Radke-Yarrow, M., Zahn-Waxler, C., \& Chapman, M. (1982). Children's prosocial dispositions and behavior. In P. Mussen (Ed.), Handbook of child psychology: Vol. IV Socialization, personality, and social development. (pp.469-545). New York: John Wiley and Sons.

Rheingold, H. (1982). Little children's participation in the work of adults, a nascent prosocial behavior. Child Development, 53, 114-125. 
Rheingold, H., \& Emery, G. (1986). The nurturant acts of very young children. In D.

Olweus, J. Block, \& M. Radke-Yarrow (Eds.), Development of antisocial and prosocial behavior: Research, theories, and issues (pp.76-96). New York: Academic Press.

Rheingold, H., Hay, D., \& West, M. (1976). Sharing in the second year of life. Child Development, 47, 1148-1158.

Smetana, J. (1984). Toddlers' social interactions regarding moral and conventional transgressions. Child Development, 포, 1767-1776.

Smith, C., Driver Leinbach, M., Stewart, B.J., \& Blackwell, J.M. (1983). Affective perspective-taking, exhortations, and children's prosocial behavior. In D.L. Bridgeman (Ed.), The nature of prosocial development: Interdisciplinary theories and strategies (pp. 113-137). New York: Academic Press.

Staub, E. (1979). Positive social behavior and morality Vol. 2: Socialization and development. New York: Academic Press.

Zahn-Waxler, C., Radke-Yarrow, M., \& King, R. (1979). Child rearing and children's prosocial initiations toward victims of distress. Child Development, $\underline{50}, 319-330$.

Zahn-Waxler, C., Radke-Yarrow, M., Wagner, E., \& Chapman, M. (1992). Development of concern for others. Developmental Psychology, 28 (1), 126-136. 


\section{Appendix A}

Minutes Videotaped as the Target Child by Measurement Point and Activity

\section{INFANTS}

\begin{tabular}{lrc} 
INFANTS & $\begin{array}{r}\text { TIME 1 } \\
2-22-94 \\
\end{array}$ \\
& $4-1-94$ \\
\hline CHILD & & \\
& GROUP ACTIVITY \\
JW* & Freeplay & 24.45 \\
& Structured play & - \\
& Mealtime & 3.58 \\
& Total & 28.03
\end{tabular}

\begin{tabular}{|c|c|c|c|c|c|}
\hline \multirow{4}{*}{$\mathrm{AH}$} & Freeplay & 27 & - & 47 & 82.03 \\
\hline & Structured play & - & - & 3 & - \\
\hline & Mealtime & - & - & 25 & - \\
\hline & Total & 27 & - & 75 & 103.03 \\
\hline \multirow{4}{*}{$\mathrm{CS}^{\wedge}$} & Freeplay & 66 & 12.75 & & \\
\hline & Structured play & & & & \\
\hline & Mealtime & 24 & 15 & & \\
\hline & Total & 90 & 27.75 & & \\
\hline \multirow{4}{*}{ SM } & Freeplay & 53 & 30 & 66 & 69.87 \\
\hline & Structured play & - & - & - & - \\
\hline & Mealtime & 13 & - & 3 & 24 \\
\hline & Total & 66 & 30 & 69 & 93.87 \\
\hline \multirow{4}{*}{$\mathrm{AH}$} & Freeplay & 48 & 71.5 & 66.88 & 69.87 \\
\hline & Structured play & - & - & - & - \\
\hline & Mealtime & 42 & 1 & 36 & 24 \\
\hline & Total & 90 & 72.5 & 102.88 & 93.87 \\
\hline \multirow{4}{*}{ JS } & Freeplay & 43 & 51.05 & 81 & 117.5 \\
\hline & Structured play & - & - & - & - \\
\hline & Mealtime & 15 & 12 & 27 & 34.5 \\
\hline & Total & 58 & 63.05 & 108 & 152 \\
\hline
\end{tabular}

* Cross-Sectional Sample

$\wedge$ Participation Discontinued 
INFANTS

TIME 1

TIME 2

TIME 3

TIME 4

2-22-94 to

4-11-94 to

6-6-94 to

8-1-94 to

4-1-94 5-5-94 6-28-94 GROUP ACTIVITY

\begin{tabular}{|c|c|c|c|c|c|}
\hline $\mathrm{CF}^{*}$ & $\begin{array}{r}\text { Freeplay } \\
\text { Structured play } \\
\text { Mealtime } \\
\text { Total }\end{array}$ & $\begin{array}{l}79 \\
- \\
10.75 \\
89.45\end{array}$ & & & \\
\hline SE & $\begin{array}{r}\text { Freeplay } \\
\text { Structured play } \\
\text { Mealtime } \\
\text { Total }\end{array}$ & $\begin{array}{l}52.5 \\
- \\
34.5 \\
87\end{array}$ & $\begin{array}{c}97 \\
- \\
10.83 \\
107.83\end{array}$ & $\begin{array}{c}56.28 \\
3 \\
33.67 \\
92.95\end{array}$ & $\begin{array}{c}83.87 \\
- \\
24 \\
107.87\end{array}$ \\
\hline $\mathrm{SA}^{* \wedge}$ & $\begin{array}{r}\text { Freeplay } \\
\text { Structured play } \\
\text { Mealtime } \\
\text { Total }\end{array}$ & $\begin{array}{l}59.5 \\
- \\
15.5 \\
75\end{array}$ & & & \\
\hline $\mathrm{DD}^{*}$ & $\begin{array}{r}\text { Freeplay } \\
\text { Structured play } \\
\text { Mealtime } \\
\text { Total }\end{array}$ & $\begin{array}{l}62.5 \\
- \\
16.5 \\
79\end{array}$ & & & \\
\hline $\mathrm{KT}$ & $\begin{array}{r}\text { Freeplay } \\
\text { Structured play } \\
\text { Mealtime } \\
\text { Total }\end{array}$ & $\begin{array}{l}49.5 \\
- \\
28.5 \\
78\end{array}$ & $\begin{array}{c}59.78 \\
6 \\
5.8 \\
71.58\end{array}$ & $\begin{array}{c}84.27 \\
- \\
16.5 \\
100.77\end{array}$ & $\begin{array}{r}97 \\
- \\
21 \\
118\end{array}$ \\
\hline
\end{tabular}

\begin{tabular}{rrc}
\hline ML & Freeplay & 69.25 \\
& Structured play & - \\
Mealtime & 31.75 \\
Total & 101 \\
\hline CC* & Freeplay & 71.58 \\
& Structured play & - \\
Mealtime & 18 \\
Total & 89.58 \\
\hline
\end{tabular}

\footnotetext{
* Cross-Sectional Sample

^ Participation Discontinued
} 


\begin{tabular}{|c|c|c|c|c|c|}
\hline \multirow{2}{*}{\multicolumn{2}{|c|}{ TODDLERS }} & \multirow{2}{*}{$\begin{array}{c}\text { TIME } 1 \\
2-22-94 \text { to } \\
4-1-94 \\
\end{array}$} & \multicolumn{2}{|c|}{ Prosocial Behaviors } & \multirow{2}{*}{$\begin{array}{r}64 \\
\text { TIME } 4 \\
8-1-94 \text { to } \\
8-23-94 \\
\end{array}$} \\
\hline & & & & TIME 3 & \\
\hline \multirow[t]{2}{*}{ CHILD } & GROUP ACTIVITY & & & & \\
\hline & Freeplay & 54 & 28 & 83.75 & 108 \\
\hline \multirow[t]{4}{*}{ VP } & Structured play & 15 & 21 & 12 & 6 \\
\hline & Mealtime & 30.67 & 33 & 10 & 18 \\
\hline & Total & 99.67 & 82 & 105.75 & 132 \\
\hline & Freeplay & 47 & 68.17 & 39 & 91.25 \\
\hline \multirow[t]{4}{*}{ PK } & Structured play & 4 & 6 & - & 3 \\
\hline & Mealtime & 21 & 29 & 12 & 15 \\
\hline & Total & 72 & 103.17 & 51 & 109.25 \\
\hline & Freeplay & 55.38 & & & \\
\hline \multirow[t]{4}{*}{$\mathrm{KM}^{*}$} & Structured play & 8.5 & & & \\
\hline & Mealtime & 18 & & & \\
\hline & Total & 81.88 & & & \\
\hline & Freeplay & 62 & 60 & 76.75 & 88 \\
\hline \multirow[t]{4}{*}{$\mathrm{AL}$} & Structured play & - & 3 & 6 & - \\
\hline & Mealtime & 21 & 21 & 14.03 & 12 \\
\hline & Total & 83 & 84 & 96.78 & 100 \\
\hline & Freeplay & 55.5 & 53.5 & 81.25 & 108 \\
\hline \multirow[t]{4}{*}{ KW } & Structured play & 13.5 & 6 & 9 & 9 \\
\hline & Mealtime & 24 & 42 & 15 & 9 \\
\hline & Total & 93 & 101.5 & 105.25 & 126 \\
\hline & Freeplay & 56 & 28.5 & 61.22 & 85.22 \\
\hline \multirow[t]{4}{*}{$\mathrm{SD}$} & Structured play & 13 & 3 & 18 & - \\
\hline & Mealtime & 17 & 13.5 & 24 & 24 \\
\hline & Total & 86 & 45 & 103.22 & 109.22 \\
\hline & Freeplay & 51.5 & & & \\
\hline \multirow[t]{3}{*}{$\mathrm{RC}^{*}$} & Structured play & - & & & \\
\hline & Mealtime & 5 & & & \\
\hline & Total & 56.5 & & & \\
\hline
\end{tabular}

* Cross-Sectional Sample

$\wedge$ Participation Discontinued 


\begin{tabular}{|c|c|c|c|c|c|}
\hline \multicolumn{2}{|c|}{ TODDLERS } & \multirow{2}{*}{$\begin{array}{c}\text { TIME } 1 \\
2-22-94 \text { to } \\
4-1-94\end{array}$} & \multirow{2}{*}{$\begin{array}{l}\text { TIME } 2 \\
4-11-94 \text { to } \\
5-5-94\end{array}$} & \multirow{2}{*}{$\begin{array}{l}\text { TIME } 3 \\
6-6-94 \text { to } \\
6-28-94 \\
\end{array}$} & \multirow{2}{*}{$\begin{array}{r}\text { TIME } 4 \\
8-1-94 \text { to } \\
8-23-94 \\
\end{array}$} \\
\hline CHILD & GROUP ACTIVITY & & & & \\
\hline & Freeplay & 43.25 & 74.5 & 75.87 & 96 \\
\hline \multirow[t]{4}{*}{$\mathrm{CS}$} & Structured play & 6 & 6 & 3 & - \\
\hline & Mealtime & 22.75 & 36 & 21 & 18 \\
\hline & Total & 72 & 116.5 & 99.87 & 114 \\
\hline & Freeplay & 55 & 57.83 & 72 & 92.32 \\
\hline \multirow[t]{4}{*}{ ZS } & Structured play & 16 & 6 & 15 & 1.5 \\
\hline & Mealtime & 17 & 21.5 & 12 & 27 \\
\hline & Total & 88 & 85.33 & 99 & 120.82 \\
\hline & Freeplay & 44 & 26.42 & 40 & 74.98 \\
\hline \multirow[t]{4}{*}{ KM } & Structured play & 7 & 12 & 14 & - \\
\hline & Mealtime & 16 & 30 & 15 & 13.5 \\
\hline & Total & 67 & 68.42 & 69 & 88.48 \\
\hline & Freeplay & 53.75 & 60.17 & 63 & 95.03 \\
\hline \multirow[t]{3}{*}{$\mathrm{AJ}$} & Structured play & 12.5 & 9 & 6 & 1.5 \\
\hline & Mealtime & 23.75 & 42 & 24 & 24 \\
\hline & Total & 90 & 111.17 & 93 & 120.53 \\
\hline
\end{tabular}

* Cross-Sectional Sample

^ Participation Discontinued 


\begin{tabular}{|c|c|c|c|c|c|}
\hline \multicolumn{2}{|c|}{ TRANSITIONERS } & $\begin{array}{c}\text { TIME } 1 \\
2-22-94 \text { to } \\
4-1-94\end{array}$ & $\begin{array}{l}\text { TIME } 2 \\
4-11-94 \text { to } \\
5-5-94 \\
\end{array}$ & $\begin{array}{l}\text { TIME } 3 \\
6-6-94 \text { to } \\
6-28-94 \\
\end{array}$ & $\begin{array}{r}\text { TIME } 4 \\
8-1-94 \text { to } \\
8-23-94 \\
\end{array}$ \\
\hline \multirow[t]{2}{*}{ CHILD } & GROUP ACTIVITY & & & & \\
\hline & Freeplay & 60.5 & 82.33 & 58.9 & 81 \\
\hline \multirow[t]{4}{*}{$\mathrm{BF}$} & Structured play & 7.5 & 3 & 18 & 12 \\
\hline & Mealtime & 21 & 24 & 28.5 & 24 \\
\hline & Total & 89 & 109.33 & 105.4 & 117 \\
\hline & Freeplay & 36 & 27 & 60.03 & 63.6 \\
\hline \multirow[t]{4}{*}{$\mathrm{JC}$} & Structured play & 3 & 9 & 15 & 9 \\
\hline & Mealtime & 16 & 12 & 22.87 & 1.5 \\
\hline & Total & 55 & 48 & 95.9 & 74.1 \\
\hline & Freeplay & 74.33 & & & \\
\hline \multirow[t]{4}{*}{$\mathrm{AC}^{*}$} & Structured play & 12 & & & \\
\hline & Mealtime & 18 & & & \\
\hline & Total & 104.33 & & & \\
\hline & Freeplay & 53 & & & \\
\hline \multirow[t]{4}{*}{$\mathrm{DB}^{*}$} & Structured play & 3 & & & \\
\hline & Mealtime & 12 & & & \\
\hline & Total & 69 & & & \\
\hline & Freeplay & 65.5 & 83 & 56.67 & 106.85 \\
\hline \multirow[t]{4}{*}{$\mathrm{CS}$} & Structured play & 8.83 & 6 & 12 & 6 \\
\hline & Mealtime & 24 & 17 & 30 & 19.63 \\
\hline & Total & 98.33 & 106 & 98.67 & 132.48 \\
\hline & Freeplay & 56 & & & \\
\hline \multirow[t]{4}{*}{$\mathrm{JK}^{*}$} & Structured play & 21 & & & \\
\hline & Mealtime & 18 & & & \\
\hline & Total & 95 & & & \\
\hline & Freeplay & 45.75 & 73.25 & 57 & 79.45 \\
\hline \multirow[t]{3}{*}{$\mathrm{KL}$} & Structured play & 10.25 & 5 & 15 & 9 \\
\hline & Mealtime & 25 & 24 & 36 & 12 \\
\hline & Total & 81 & 102.25 & 108 & 100.45 \\
\hline
\end{tabular}

* Cross-Sectional Sample

$\wedge$ Participation Discontinued 
TRANSITIONERS

TIME 1

2-22-94 to 4-1-94 GROUP ACTIVITY

CHILD

$\begin{array}{rrc} & \text { Freeplay } & 107.5 \\ \text { EA* }^{*} & \text { Structured play } & 20.5 \\ & \text { Mealtime } & 24.42 \\ & \text { Total } & 152.42\end{array}$

\begin{tabular}{|c|c|c|c|c|c|}
\hline & Freeplay & 63.83 & 58.78 & 557 & 51 \\
\hline \multirow{4}{*}{ CR } & Structured play & 8 & 9 & 24 & 6 \\
\hline & Mealtime & 26.17 & 28 & 31 & 30 \\
\hline & Total & 98 & 95.78 & 110.7 & 87 \\
\hline & Freeplay & 129 & & & \\
\hline \multirow[t]{4}{*}{$\mathrm{JZ}^{*}$} & Structured play & 12 & & & \\
\hline & Mealtime & 29.17 & & & \\
\hline & Total & 170.17 & & & \\
\hline & Freeplay & 34.75 & & & \\
\hline \multirow[t]{4}{*}{$\mathrm{N}^{*}$} & Structured play & 9 & & & \\
\hline & Mealtime & 6 & & & \\
\hline & Total & 49.75 & & & \\
\hline & Freeplay & 44 & 51.63 & 48.25 & \\
\hline \multirow[t]{4}{*}{$\mathrm{CT}^{\wedge}$} & Structured play & 9 & 10.18 & 4.5 & \\
\hline & Mealtime & 7 & 21 & 30 & \\
\hline & Total & 60 & 82.81 & 82.75 & \\
\hline & Freeplay & 111 & & & \\
\hline \multirow[t]{3}{*}{ MS* } & Structured play & 16.08 & & & \\
\hline & Mealtime & 13.75 & & & \\
\hline & Total & 140.83 & & & \\
\hline
\end{tabular}

TIME 2

4-11-94 to

TIME 3

TIME 4 5-5-94

8-1-94 to 8-23-94 


\section{Appendix B}

\section{Prosocial Behaviors}

\section{The Origins of Caring: Coding Manual}

1. Solitary-(SOL) -- Solitary behavior will be coded if there is an absence of social behavior and other code able behaviors (social behavior includes speaking or vocalizing, and listening when addressed). The solitary category includes unoccupied behavior (must be more than three feet away from anyone with no eye gaze directed at another and no mutual interest in object or activity and no parallel play). If the previous code was solitary or ONGO-solitary and a potential social partner approaches within three feet but the target child does not look up or otherwise acknowledge, still code as solitary. Never code solitary as an event, always wait until an entire 10 second interval has elapsed to code a change. The child must be solitary for an entire 10 second interval before SOL can be coded.

2. Social Behavior- (SOC) -- Child makes eye contact, vocalizes, smiles, laughs, makes purposeful. nonaggressive physical contact, or participates in a joint activity with at least one other person. This category also includes attending to peer or caregiver, engaging in parallel activity with some mutual awareness or similar objects, leading/ following/ imitating when peer-initiated (see entry bid for self-initiated), participating in social games or play, or being a recipient of adult caregiving. Also includes onlooking behavior (i.e., watching others, including the camera person, without making or responding to entry bids or engaging in parallel activities). This category is to be coded any time the target child is within three feet of another person; however, do not count fleeting instances ( 3 seconds or less). For example, if a child briefly rides within three feet of another while riding a trike but does not stop or engage other, do not code as social. Never code social as an event, wait until an entire 10s interval has elapsed to code a change.

Coding Strategy: When coding SOC and SOL, if child is coded as SOC, SOC, 
SOC, and then at the ten second snapshot has just become SOL still code as SOC, and if child remains SOL for next ten seconds code as SOL.

3. Entry Bid - (ENT)--Any behavior performed by the child that is an obvious, focused attempt to gain attention with the intent to initiate a new social interaction. Failed attempts are also coded. Entry bids include the target child's attempts to play with others or to join in his/ her/ their activity. Focused attempts to gain attention must include looking at the social partner and one of the following:

--Any codeable behavior (e.g., AFF-entry bid, RV-entry bid, etc.) that initiates a new social interaction.

-- A verbal requests to play such as "Can I get in your fort?"; invitations to play such as holding a bike next to one's own bike and saying "There's a bike for you over here". In some cases, vocalizations without meaning are included.

-- A gesture such as beckoning or persistent hello-waving (10s or more).

-- Obvious imitative actions such as hopping on one foot.

-- Initiation of parallel play involving similar objects (side-by-side play with blocks) or actions (follow -the-leader). If the camera view is from behind and the coder cannot tell where the target child is looking (where his / her line of sight is directed) do not code entry bid. If it is discernable that the child is looking at social partners while initiating parallel activity then code entry bid.

-- Any other non-aversive behavior that appears to have the intent of beginning a new social interaction.

In general, entry bids are self-initiated. Only in rare cases when a teacher or another person suggests that the target child make an entry bid will this code be otherinitiated.

If the social interaction is very brief, to determine if a social interaction is an entry 
bid, other factors such as the maintenance of close physical proximitiy or lingering glances may indicate that the child's intent was to initiate a sustained social interaction and that an entry bid has been made.

If the target child leaves a group or individual with whom he / she had been interacting, do not code the target child's return to the group or individual as an entry bid.

4. Teacher Prompts- (TP)--Any suggestion, request, prompt, or command directed toward the focal child or group of children that includes the target child (do not code a teacher prompt that is directed at specific other children). Some teacher prompts are direct requests. Direct requests specify an immediate course of action (or the cessation of an activity) and do not involve a choice. Many times teacher prompts pertain to rules of the child care center (listed in the compliance and noncompliance codes). Examples of teacher prompts include "It's cleanup time!", "I think you forgot to put your sweater away", "Stop your body", and almost any statement beginning with "You need to..." or "I need you too...". Some teacher prompts may be worded in such a way as to give the illusion of choice such as "You may want to put your dishes in the tubs". In almost all cases, the code following a direct request teacher prompt is either compliance or noncompliance. In this case, the code following a teacher prompt code is initiated by and probably directed to an adult; however, if a teacher prompts the target child to do something and then does it for them (particularly infants) before 10 seconds elapses, the next behavior coded will not necessarily be initiated by or directed toward an adult (there is not a NON-O or COMP coded in this case). Some teacher prompts have a duration of several seconds so wait until it is completed to code. This may result in a teacher prompt being coded more than ten seconds after the previous code. For example, if a teacher begins to prompt the target child seven seconds after the previous code and the prompt has a duration of five seconds, coding the TP when it is completed will put it twelve 
seconds between the two codes. This is the only code for which it is permissible to have more than 10 seconds between codes. Also code obvious nonverbal prompts made by the teacher such as putting a container directly in front of a child who possess an object that belongs in the container (a prompt to put the object away). See 'Rule for Coding Responses to Direct Request Teacher Prompts' following the description of Noncompliance (\#18).

Determining the number of events: If the teacher prompts the child repeatedly to do the same thing without letting ten seconds elapse in between prompts, only code once. For example, "You need to sit down with your food....please sit down...you should sit down..." all within ten seconds, code once at end of the last statement.

5. Assertive Problem Solving- (APS)-- This category is designed to reflect the use of assertive problem solving strategies recommended by the teachers to the children at the child care center. These strategies are primarily verbal statements designed to avoid or resolve conflicts between peers and are suggested by the teachers as an alternative style for interacting with each other in situations which may otherwise result in undesired behaviors such as resource violations or physical aggression. Examples include asking "Can I use it next?" to a child who has a desired toy; "I'm using that", or "I didn't see your hands on it" to a child who is vying for possession of an object; saying "Stop!", "Don't", or "Move away from me" to a child who is crowding in. To be coded as APS, the statement must be made to the child to whom it is directed or to a teacher when the child to whom it is directed is within earshot. This type of assertive problem solving may be self-initiated or be in response to a teacher prompt. An example of an adult-initiated APS would be delivering the message "I don't like it when you take my toys, it makes me very mad!" to another child following the teacher prompt: "Use your words and tell them". Also note: In some instances APS will be coded when it does not appear to be a prosocial behavior and may even appear as a selfish behavior such as when a child says 
"Move away" or "NO! I'm using it!" in a not-so-friendly voice; asking for food or to have food passed at mealtime is not considered APS. Do not code APS if the child is commiting RV simultaneously.

Determining the number of events: In these situations when the behavior is a verbalization, code each time the child makes a separate attempt to communicates long as there has been an intervening time between attempts that is long enough in duration so that social partner could have responded. "Canluseitnext, CanIuseitnext, CanIbenext, CanIplease, Canl?" is only coded as one act of assertive problem solving because there was no chance for social partner to respond in between requests. If no response is expected (e.g., "Move away, there's not enough room") count each statement as an event. If child repeats same APS statement to same social partner or group of social partner, code subsequent occurrences as ONGO, as long as there is no intervening coded behavior.

\section{PROSOCIAL BEHAVIORS}

NOTE: If any of the following Prosocial behaviors are directed towards an individual in distress, code as CD ( see Comfort/concern for distressed, p.77).

6. Pointing- (P)--Child extends arm and index finger toward a stimulus. If other fingers are extended in addition to the index finger (with the exception of the thumb), this is considered reaching as opposed to pointing and is not a coded event.

Determining the number of events: Count as another point if child retracts index finger making a fist and points again or extends other fingers and then reclenches them and points again. If a child points with both hands simultaneously, code as only one event. Count as another event if child brings arm down or in and re-extends even if finger is still in the 'point' position.

7. Showing- (SHOW)--Child holds up an object toward another person while 
looking at other person but does not relinquish control of the object. This category includes showing clean hands or scraped knees or other body parts (belly buttons or bruises, or articles of clothing that cannot be held up). This category also includes 'partial shares' (i.e., the child offers up an object to another person to hold or grab but also retains possession). Also code if child shows a stationary object to someone by using verbalizations / vocalizations, or gestures to draw social partners attention to object.

Determining the number of events: Count as another show each time arm is extended or brought up again (even with same object or same social partner regardless of verbalization ( e.g., "look at this, look at this, look at this" is only one show unless above happens)).

8. Sharing- (SHR)--Child voluntarily relinquishes an object to another that was in his/her possession or that he/she was using. This category will include most forms of resource transfers that do not appear to be accidental. Voluntarily relinquishing an object that is being grabbed by a peer is not considered sharing. Returning an object that was obtained via resource violation is not considered sharing. A resource transfer that is being coded as a HELP such as when child returns dropped or lost object is not also coded as a share. This category is also coded if child shares his/her space with another by moving his/her body to make room for another. The space must be occupied by the target child prior to sharing in order to be considered sharing. 'Sharing' trash with a teacher is to be considered rule compliance.

Determining the number of events: To be counted as another share the child must share a new object, share with a different social partner, or be involved in some type of turn-taking activity in which they (child and social partner(s)) share the same object with each other repeatedly. If a child shares two objects simultaneously, this is coded as one share.

9. Helping- (HELP)--Child provides any form of task assistance for other persons 
that is not considered participation in the work of adults. This category includes attempts to alleviate another person's nonemotional needs, e.g., finding a lost object or retrieving a dropped object, throwing back a ball that was hit (assuming that the focal child was not playing ball but was in a position to return it to the players), cleaning up another's spill (or when it is not possible to determine who caused spill), and passing food at the table. When a child returns an object that was lost or dropped, it is not considered a share. If a child picks up a dropped object but makes no effort to return it to the person who dropped it, it is not considered a 'help' (if help has already been coded because the process lasted longer than ten seconds and the coder estimated that the child was physically moving toward a "Help", code RV or NonCo at the end of the following ten second interval if it is determined that the child has decided to keep the object). HELP is coded when a child responds appropriately to a request beginning with "Would you go get me a... " when the object the child is retreiving is needed by another (if the object is for the target child, code COMP). Also includes teaching (i.e., child provides verbal instructions or advice apparently designed to facilitate another person's attempted or ongoing activity, or a nonverbal demonstration of activity with accompanying verbalizations designed to provide instructions (e.g., "do it like this")). Helping can be directed to a peer, adult, or somebody (but not nobody).

10. Performing the work of adults- (PWA)-- Child performs tasks of adults in the child care setting that are similar to domestic tasks (e.g., folding laundry, vacuuming or sweeping, wiping down tables when there is no visible spill, setting table, carrying food from the meal cart or kitchen to the table, or setting up the the tubs and bucket from the meal cart in preparation for mealtime utensil cleanup, or watering plants (if this is not a pretend activity)). These are tasks that are not considered to be the child's "duties", nor are they required by the rules of the center. Do not code behaviors that appear to be more play than work such as pushing a toy plastic lawn mower. Also do not code any 
structured activities as PWA. PWA is always directed towards an adult.

11. Caregiving- (Care) Child displays nurturant or affectionate acts toward dolls, animals, or representations of dolls or animals (does not include keys or blankets). Playing with dolls and animals is not necessarily considered caregiving (pulling an animal pull-toy is not considered caregiving, carrying, in and of itself, is not considered caregiving). The child must be performing some nurturant behavior toward the doll or animal that is similar to the type of caregiving that parents perform for their children (i.e., walking a doll around is not considered caregiving but teaching a doll to walk is). This category includes holding the doll in a nurturant manner (cradling it), transporting with sustained attention (pushing a doll with a blanket around in a stroller), feeding, grooming, bedding, dressing, pointing/showing/sharing with, caressing, or performing any other prosocial behavior towards doll or animal. Also code if child performs any of the above with a real person during symbolic or pretend play (e.g., affectionately patting or petting of peer who is pretending to be an animal, or feeding a baby in mommy / baby pretend play). Coders should become sensitized to the caregiving category when caregiving materials such as dolls, blankets, cribs, strollers, etc. are visible. To begin coding caregiving, there must be a discrete caregiving event which entails physical contact with the doll or animal or between dolls and animals. There is more stringent criteria for a "new" caregiving code (the onset) than an "Ongo" caregiving code. After the onset, code all activities that are pertinent to caregiving such as folding a blanket, sifting through doll clothes, arranging a crib, or talking with a teacher about caregiving or enlisting a teacher's assistance in caregiving, as "Ongo". Stop coding Caregiving if the child's attention is displaced for a more than one entire 10 s interval (i.e., the child drops all caregiving materials and turns his / her back to them) or if the behavior toward the animal/doll becomes non-nurturant (swinging a doll by the hair). Wait until the next ten second interval ends to code a new behavior category (unless there is a discrete event 
from another behavior category).

12. Affection- (AFF)-- Child hugs, pats, kisses, holds hands with, or intentionally touches another in a positive manner (if AFF is directed toward a doll, animal, or representation of a doll / animal code as CARE). Also code attempts at affection such as holding up arms to be picked up but not getting picked up or trying to sit on teacher's lap but missing. Also code verbal affection such as "will you hold me?", or "can I hug you?". If a child is the recipient of affection (a hug for example) and responds or reacts in a manner consistent with the affection code (child puts arms around person who is hugging him/her) then code as other-initiated affection for target child. However, if the child does not respond (stands with arms at side while being hugged) do not code. Do not code neutral touches (when touches are part of a game such as holding hands to play ringaround-the-rosie) or instrumental touches (for balance, to gain access, to get another's attention, or when being led by a teacher). Sitting in a teacher's lap and being picked up and carried are to be coded in the same way. When a child sits in a teacher's lap or is picked up, code affection once, but do not code as ONGO unless child performs another new accompanying affectionate behavior. If the interval begins and the child is already sitting in a teacher's lap, code "other-initiated" affection at the ten second point otherwise code as an event when it happens.

Determining the number of events: Count as another event if there is physical separation between social partners and the criteria for affection is met again following separation.

13. Distress to distress- (DD)-- Child shows a negative emotion to another person's distress, including crying, sobbing, fretting, whimpering, or having a cryface. Will always be self-initiated.

Determining the number of events: Count as another event if the child attends to something other than distressed individual, regains positive or neutral affect 
and subsequently meets the criteria for DD.

14. Attention to distress- (AD)-- Child, at least momentarily, looks at or in direction of distressed person; also code if child is already looking at a person who becomes distressed and continues looking. Will alomost always be self-initiated. Will only be other-initiated if someone else suggests that the child attend by making a comment like "Look!", or by pointing.

Determining the number of events: Count as another event if the child attends to something other than the distressed individual and then looks back and meets the criteria for $\mathrm{AD}$ again.

15. Comfort/concern for distressed-(CD) Child verbally or physically attempts to console, help, or intervene on behalf of distressed person. This category includes offering physical comfort (i.e., hugs, pats, kisses, rubs, bringing ice to a wounded peer or a bottle to a crying baby, or applying a bandage), verbal comfort or sympathetic statements ("You be okay"; "Are you okay?"), verbal advice (e.g., "be careful", "rub it!"), verbal hypothesis testing ( "baby cry cause mommy gone"), or help to the distressed individual. In addition, this category will be coded if a child shares with a distressed individual, attempts to find adult caregiver, attempts to prevent further distress by distracting the distressed individual, or attempts to discern the cause of distress.

16. Rule Compliance-(COMP)-- the child performs behaviors that are required or expected as rules of the center. In general these rules involve A) cleaning up after self or other self-care activities and B) not hurting others/ safety considerations. Rules that involve cleaning up after self/self-care entail performing visible behaviors and will be coded as rule compliance. Rules that involve not hurting others demand the regulation or inhibition of behaviors. For this reason, transgressions of these rules will be coded as noncompliance or physical aggression. If a compliant behavior can be coded in another prosocial behavior category, code it in that category (i.e., adult-initiated share). If a child 
is simultaneously complying (physically) but verbally objecting, still code compliance. Code compliance whenever a compliant event occurs even if this results in the coding of the same behavior twice (for example, compliance is coded 10s after teacher prompt if the coder judges the child to be on his/her way to complying and 5 seconds after that when the actual event occurs). In this case, the compliance event will be coded as Ongo.

A. Rules concerning cleaning up after self and self-care:

I) All objects belong in their proper place--

--Toys must be put away at designated times into their proper place. During free play, children are free to put toys or objects used as toys anywhere. Putting toys away at designated times is scored as adult requested rule compliance. Spontaneous rule compliance is coded when child puts away toys at times other than clean-up time (i.e., when they are finished with them).

--Trash (e.g., used kleenex) should be thrown away or given to teachers.

--Eating utensils must be returned to the meal cart after meals and snacks. Each trip to the meal cart counts as one act of compliance.

--Children are required to hang coats and store personal items in their own cubby space (they are also required to put their coat on before going outside if it is cold). For some structured activities, wearing a smock is also required. In order to code wearing a smock or coat as rule compliance the act of actually putting it on must be observed (if a threeminute interval begins with child wearing a smock or coat 
do not score, you must see him/her put it on).

II ) Any time hands are washed code compliance.

Before mealtime, code as adult initiated compliance if there is a general pronouncement that it is hand-washing time (may be in the form of a teacher prompt regarding mealtime and getting ready for mealtime). For infants and toddlers, adult-initiated compliance can consist of permitting (i.e., not resisting) caregiver attempts to wipe hands, face, or nose. For face wipes and nose blows, turning the head to the side (one turn, one direction) does not constitute resistance and is considered compliance. To be considered resisting, child must turn head from side to side, try to physically push away hand or cloth, kick,struggle, or otherwise thwart teacher's effort. After mealtimes, children are often prompted (especially infants and toddlers) to wash hands / face or get them wiped. Do not code as Noncompliance $(\mathrm{O})$ if they don't (i.e., if there is no teacher prompt then it is not required). Code as spontaneous if child holds up hands to be washed without being prompted. If child holds up hands but they are not subsequently washed code as show.

III ) Wiping up one's own spill with a rag or towel is considered compliance. (Wiping up another's spill with a rag or towel is coded as HELP. If it is not possible to tell who caused the spill code as help.

IV ) Any compliance to a teacher's request or prompt not coded in another 
prosocial category. (See: 'Rule for coding responses to teacher prompts' located under the noncompliance category (\#18)). This includes allowing oneself to be put in a chair or physically guided, allowing a bib to be put on or removed, or being picked up without resisting.

V ) This category is also coded when a child returns an object that was obtained via resource violation or that was being used by another but not clearly enough to be considered a resource violation. (Example: Child grabs object that was sitting on table only to be informed that a teacher was saving it for a child who is in the bathroom. This does not qualify as a resource violation because it was not clearly being used but is coded as compliance when the child gives the object to the teacher. The temptation may be to code this as adult initiated sharing when it is actually adult initiated compliance in this case.)

VI ) Any time a child is waiting in line or waiting to take a turn, code compliance. If child gets in line or starts to wait, code as an event. If child is in line when sequence starts wait until ten second mark to code. If a child is waiting in line to perform another compliant behavior such as washing hands, the washing of the hands will be coded as a "New" behavior.

\section{OTHER BEHAVIOR CODES}

17. Noncompliance-(NON)-- The noncompliance category is subdivided into two 
categories: commission noncompliance and omission noncompliance. This category is almost always self-initiated. It is possible to be peer-initiated but not adult-initiated.

I.) Commission noncompliance--(CO)-- occurs when a child performs an observable noncompliant behavior (if noncompliance can be coded as an event, code NON-CO).

A. Pertaining to rules of the center:

--Child removes objects from proper place (e.g., throws arm cover of couch onto floor) unless those objects are used as toys during free play.

--Child stands or walks on furniture.

--Child takes food off food cart (does not wait to be served).

--Child engages in symbolic gun play.

--Child intentionally spills food.

--Child leaves meal area without taking eating utensils to meal cart.

B. In response to teacher prompts and requests:

--Child resists caregiver's direct request or prompt to perform a specific action. 'Resisting' includes physically struggling against caregiver, verbal protest or objection, an obvious overt avoidance behavior (e.g., hiding under mat in response to caregiver's request or prompt, physically moving away from complying ((goes opposite way from where he/she was directed by a teacher prompt)) going limp or stiff in response to request, or crying 
in protest). Also code if the child resists or

otherwise tries to avoid nose and face wipes. If

child resists request, code immediately.

--Child attempts to break a rule of the center.

NOTE: Do not code child walking while chewing as NONCO unless there has been a teacher prompt or rule statement.

II.) Omission noncompliance (O) occurs when the child fails to perform a behavior that is required or requested.

In response to teacher prompts and requests:

--Child fails to begin the process of compliance within 10 seconds following a direct caregiver request. Direct requests specify an immediate course of action and do not involve a choice ("Would you like to help me wipe the tables or play in the other room?" is not a request; "Two minutes to cleanup" is not a request).

--Child fails to begin the process of compliance within 10 seconds following a caregiver's prompt regarding rules of the center (e.g., "I don't think you put your sweater away").

NOTE: If child fails to follow rules about not taking other's possessions, code as RV.

Rule for Coding Responses to Direct Request Teacher Prompts Code the teacher prompt and reset the clock (every teacher prompt resets the clock and requires the following behavior (whatever it is) to be coded as NEW).

Wait for 10 seconds unless: (A) child avoids / resists $===>$ code Nonco (B) compliance event occurs $==>$ code Comp. 
At 10 Sec after prompt (unless (A) or (B) occurs):

If child is physically moving toward complying (in the coder's estimation) then code AI compliance.*

If child hasn't physically moved toward compliance then code noncompliance $(\mathrm{O})$.

*If after 10 seconds compliance has been coded because the coder estimates that the child is moving toward compliance and the child stops moving toward compliance during the next ten second interval, wait until the 10 interval is up and code Non-O unless there is a clear avoid / resist behavior that fits the definition of Non-Co.

18. Resource Violation-- (RV) Target child attempts to take or takes away (grab) object or toy in another's physical possession, or one that is clearly being used by another. Do not code as RV if target child is accused of RV by another child but object is not clearly being used. Coders determine what objects are clearly being used. Code RV if child takes another's food during mealtime.

19. Physical Aggression- (AGG) Child pushes, hits, kicks, bites, punches, pulls hair, yanks, pinches, spits at or otherwise intentionally physically harms another person, animal, or doll. Attempts at or threats of physical aggression are also coded. This category also includes intentionally abusing objects such as a books, other toys, or furniture (e.g., by punching, kicking, stomping on, or throwing). Physical impingements on another person that appear intentional (e.g., hard pats, obtrusive exploration of face or body (mainly for infants)) are also coded. This category is also coded if the aggression criteria is met during play (such as kicking another while playing "Let's Kick Each Other").

Determining the number of events: Count as another event if there is physical separation between social partners in between attempts or "successful" physically aggressive actions. Each time body part is extended, makes contact (or 
misses) and is withdrawn, is considered one event. If a child pummels another (rapid and repeated blows, code only one event per second). If the behaviors fit the definition of ongo (same behavior, a kick for example, to the same person) code as ONGO.

20. Off-Camera - (OC) Child cannot be seen for a period of time longer than $5 \mathrm{~s}$ and extrapolation from previous behavior cannot easily be made.

New -- new behavior same code (vacuuming, wiping down tables), new object, new social partner, or new request or prompt.

Ongoing (ONGO) --same code, same behavior, same social partner, same object, noncompliance to same request.

\section{INITIATION}

Spontaneous- "Spontaneous prosocial behaviors are those prosocial behaviors initiated by the actor without the potential recipient (or anyone else) requesting, (verbally or nonverbally) assistance... thus spontaneous acts are self-initiated (although they are often in response to situational cues that clearly indicate another's need)" (Eisenberg et al., p.107).

Asked For- "asked-for behaviors are prosocial behaviors are in response to either a verbal or nonverbal request for aid from the potential recipient (or, perhaps, a third party...asked-for prosocial behaviors are other-initiated and involve compliance with a needy other's (or a third party) request" (Eisenberg et. al., p.107). For the prosocial behaviors (except for compliance) code as other-initiated (asked for) only when there has been an obvious request directed clearly toward the target child. During coding, if you as a coder can hear a clear prompt, then assume that target child also heard prompt and code as adult or peer initiated.

There are four possible initiation codes:

--Self: the behavior is initiated by the target child 
--Peer: the behavior is initiated by another child

--Adult: the behavior is initiated by an adult

--Other: the behavior is mutually initiated or the initiator is indeterminable

\section{DIRECTION}

The "Direction" specifies the recipient of the target child's behavior.

--Peer- another child, or group of children

--Adult- teacher, parent, maintenance personnel, or any other adult

--Somebody- animals, dolls, or if there is more than one social partner and includes at least one adult and one peer, or if we know there is a social partner but he / she is off screen.

--Nobody- If there is no observable social partner or the behavior is directed at no one in particular (such as self-initiated compliance-throwing away trash). Also includes self-initiated behaviors that are completed to comply with rules of the center (prompted compliance [adult-initiated] is directed toward adults).

\section{ACTIVITY}

The camera person was instructed to note activity on the log sheet that was kept. Only code other then the camera person denoted if it is clear that a mistake has been made.

Free play-- Child partakes in self-directed, self-chosen activities using any of the available resources (toys, books, etc.). Play in the multi-purpose room is considered free play as well as most outdoor play.

Structured Play-- Structured play is an activity initiated by a teacher who directly supervises and sometimes participates in the activity. It involves limited resources such as clay, paint, chalk, contact paper, cooking materials, etc., which are controlled and distributed by the supervising teacher. Most indoor structured activites take place in the 
meal areas. Other examples of structured activities include water tables, sand tables, making necklaces, preparing food, planting plants, and playing with flubber (flubber is similiar to play-doh or silly-putty), etc. Some activites (in particular, the swinging ball and bat in the barn) can either be structured or free play depending on whether or not there is a supervising teacher.

Mealtime-- Children eat as a group three different times a day (morning snack, lunch, and afternoon snack). Code mealtime even if the target child has chosen to abstain from the meal (if everyone else is at mealtime).

\section{CODING STRATEGIES}

A behavior must be witnessed to be coded; for instance, a three minute interval begins with a child wearing a smock is not coded as compliance ---only if we actually see child put on smock do we code compliance.

Code events at their culmination (e.g., if a child is showing another some object wait until he / she finishes showing the object (puts arm down, or otherwise pulls away to code). If you are waiting for an event to end and you reach ten-seconds from the last code, code the behavior at that point in time (10s). Other examples include waiting until a teacher has finished speaking to code TP, or waiting until 10s after a child has started to wash hands before coding COMP because the behavior lasts longer than 10s.

Coding Verbal Statements: Verbal statements or requests regarding coded behaviors such as "Will you hold me?", "I want to hug you", "I need my hands wiped", "I need a bib" are coded in the appropriate category. If a child says, "I need a bib", code compliance. If the bib is put on and this behavior is observable, code a new compliance.

If two behaviors occur at exactly the same time, if one is an event and the other is a process, code the process behavior first, then the event. 


\section{Prosocial Behaviors \\ Approximate Daily Schedule

Arrival time to roughly 9:00 AM.-- For infants, free play. For toddlers and transitioners, free play and structured play choice. This time always ends with a "clean-up" time just before the morning snack.

9:00 to 9:30-- Morning snack time. The mealcart for the infants usually arrives between 9:00 and 9:15. Shortly thereafter, the mealcarts for the toddlers and transitioners are delivered.

10:00 to 11:30-- For infants, free play and nap time if necessary. For toddlers and transitioners, free play or structured play choices, and on some days multi-purpose room play.

11:30 to 12:00-- Lunch time. There is always a "clean-up" time before lunch.

12:00 to 2:00-- Nap time.

2:00 to 3:30-- For infants, free play. For transitioners and toddlers, free play and structured play choices. There is always a "cleanup time" before afternoon snack.

3:30 to 4:00-- Afternoon snack.

4:00 until departure-- Free play for all classrooms.

---NOTE: This is an approximate schedule, do not code based on time of day. 